\title{
Evaluation of Bismuth Added HMO Glasses in Terms of Thermal, Mechanical, Gamma Radiation Shielding and Thermoluminescence Properties
}

\author{
Ashwitha Nancy D'Souza ${ }^{a}$, K. Sharmila ${ }^{b}$ D. K. Gaikwad ${ }^{c}$ M. I. Sayyed ${ }^{d, e}$, H. M. Somashekarappa ${ }^{b}$, \\ Hanan Al-Ghamdif, Aljawhara H. Almuqrinf, Sudha D. Kamath ${ }^{a}$ (D) \\ ${ }^{a}$ Manipal Academy of Higher Education, Manipal Institute of Technology, Department of Physics, \\ Manipal, India. \\ ${ }^{b}$ Mangalore University, Centre for application of Radioisotopes and Radiation Technology, Mangalore, India. \\ ${ }^{c}$ Dr. Babasaheb Ambedkar Marathwada University, Department of Physics, 431004, Aurangabad, India. \\ ${ }^{d}$ Faculty of Science, Department of Physics, Isra University, Amman, Jordan. \\ eImam Abdulrahman bin Faisal University (IAU), Institute for Research and Medical Consultations \\ (IRMC), Department of Nuclear Medicine Research, Dammam, Saudi Arabia. \\ ${ }^{f}$ Princess Nourah bint Abdulrahman University, Department of Physics, College of Science, Riyadh, \\ Saudi Arabia.
}

Received: May 22, 2021; Revised: August 15, 2021; Accepted: September 19, 2021

This article contains detailed evaluation of thermal, mechanical, radiation shielding and thermoluminescence (TL) properties of heavy metal oxide (HMO) borosilicate glasses having composition $\mathrm{xBi}_{2} \mathrm{O}_{3}-(60-\mathrm{x}) \mathrm{B}_{2} \mathrm{O}_{3}-20 \mathrm{SiO}_{2}-12 \mathrm{ZnO}-8 \mathrm{BaO}$ (with $\mathrm{x}=0,2,4,6,8,10$ and $12 \mathrm{~mol} \%$ ). Gamma shielding capacity of these glasses was examined in terms of mass attenuation coefficient (MAC) values, exposure and energy absorption build- up factor (EBF/EABF). The experimental MAC values were found to agree well with the theoretical results obtained from Photon Shielding and Dosimetry (PSD/Phy-X) software. Geometric Progression fitting method was used for the calculation of build- up factors in the photon energy region of $0.015-15 \mathrm{MeV}$ with the help of five parameters $\left(\mathrm{a}, \mathrm{b}, \mathrm{c}, \mathrm{d}\right.$ and $\mathrm{X}_{\mathrm{k}}$ ). The pattern followed by build-up factors with the gamma energy and their variation for different penetration depths up to $40 \mathrm{mfp}$ was observed and analysed. High values of equivalent atomic number and build up factors for high bismuth sample (12 mol\%) gave evidence for its improved radiation shielding capacity. Furthermore, thermoluminescence study was done to assess the suitability of the synthesized glasses as a radiation dosimeter in the gamma dose range of $0.25-30 \mathrm{kGy}$. Here, $5 \mathrm{kGy}$ irradiation exhibited major quenching in TL signal on adding bismuth to the glass network. TL performance of ZBiB-8 was noteworthy with charges trapped in high temperature trap centres with longer lifetime. TL dose response curve of ZBiB-8 showed good linearity in the dose range of $0.25-5 \mathrm{kGy}$. Fading analysis was done for this sample to find the loss in TL intensity in the course of one month. Heating the $\mathrm{ZBiB}-8$ sample to $323 \mathrm{~K}\left(50{ }^{\circ} \mathrm{C}\right)$ for $15 \mathrm{~min}$ was found to be a proper annealing condition for re-using it as a thermoluminescence dosimeter (TLD).

Keywords: Mass-attenuation coefficient (MAC), build-up (BF) factors, bismuth glasses, irradiation, thermoluminescence.

\section{Introduction}

Shielding materials used in nuclear radiation environment such as nuclear power plants, X-ray facilities, radiotherapy centres, particle accelerator centres and research laboratories would be more advantageous if they are transparent in nature ${ }^{1}$. Borosilicate glasses are known for their highly transparent nature, good radiation interaction probability, high mechanical and chemical stability ${ }^{2,3}$. However, addition of heavy metal oxides $\left(\mathrm{ZnO}, \mathrm{BaO}, \mathrm{Bi}_{2} \mathrm{O}_{3}\right)$ to such matrix would raise the effective atomic number and density of the glass composition, in turn raising the probability of interaction with radiation ${ }^{4}$.

*e-mail: sudha.kamath@manipal.edu.in
To assess the radiation shielding ability of a material, the knowledge of radiation interaction processes responsible for energy loss of radiation photons is necessary. When gamma photons interact with the material, they lose energy by three major processes- photoelectric absorption, Compton scattering and pair production process. Usually, the radiation shielding parameters are calculated by means of LambertBeer's law, which is valid only for narrow- beam geometry, monochromatic rays, and thin shielding material. In violation of any of the three conditions (broad- beam geometry), Lambert- Beer's law becomes " $\mathrm{I}=\mathrm{BI}_{0} \mathrm{e}^{-\mu t}$ " where, $\mathrm{B}$ is the correction term known as photon build- up factor ${ }^{5}$. I and $\mathrm{I}_{0}$ being intensities before and after passing through the 
shielding material, $\mu$ linear attenuation coefficient (LAC) and $t$ being thickness of the shield. When gamma photons lose their energy by Compton Scattering process inside the shielding material, their direction changes giving rise to scattered secondary photons and build up factor is used to estimate these scattered photons. When it comes to total radiation attenuation including absorption and scattering interaction by a composite material containing number of elements, the term effective atomic number $\left(Z_{\text {eff }}\right)$ is used to indicate the atomic number of the material by assuming it as a single element. Similarly, another term known as equivalent atomic number $\left(Z_{\mathrm{eq}}\right)$ is used to quantify the atomic number in case of scattering interaction process only. In addition, while the $\mathrm{Z}_{\text {eff }}$ parameter has the highest values in the photoelectric region where absorption is dominant, $\mathrm{Z}_{\text {eq }}$ takes maximum values in the region where Compton scattering is dominant. Gamma ray build- up factor (BF) is a multiplicative factor and can be defined as the ratio of total detector response to un- collided photons. Build-up factors are of two types- exposure build-up factor (EBF) and energy absorption build-up factor (EABF). In case of $\mathrm{EBF}$, the focus is on exposure and the detector response is a function of energy absorption in air. Whereas in case of EABF, energy absorbed or deposited is the matter of interest and the detector response is a function of absorption in the material $^{1}$. To obtain the build- up factors for the shielding material, geometric progression (GP) fitting formula was developed by Harima et. $\mathrm{al}^{6}$. This formula is found to be accurate within $5 \%$ of uncertainty and is able to reproduce the data over entire range of distance, energy and atomic number within few percent ${ }^{7-9}$. BFs have been calculated and explored for different shielding materials such as concretes in many literatures ${ }^{1,7}$.

Thermoluminescent dosimeters (TLD) are being used for high radiation dosimetry in radiation environment such as food irradiation, radiotherapy and nuclear power plants ${ }^{10}$. Many TLDs such as LiF:Mg, Ti and $\mathrm{Li}_{2} \mathrm{~B}_{4} \mathrm{O}_{7}$ :Mn with good sensitivity and reproducibility have been developed ${ }^{11,12}$. But, glasses would be good candidates for TLD application because of their properties such as good heat resistance, anti-corrosion, anti-wear and light weight ${ }^{13}$. When radiation interacts with the glass network, secondary electrons and non- bridging oxygens are formed which are responsible for TL glow curves ${ }^{14}$. It has been reported that adding bismuth to the network causes quenching in TL intensity ${ }^{15}$. No much study has been done on the influence of $\mathrm{Bi}^{3+}$ ions on TL glow curves. The purpose of the present study is to investigate the depth of trap centres and half- life of charges trapped in them along with the evaluation of fading of TL glow curves, sensitivity, reproducibility, and effective atomic number of the optimum sample at optimum dose.
In the present investigation, the mass attenuation coefficient (MAC) values were determined theoretically and experimentally for bismuth varied zinc barium borosilicate glasses at different gamma energies. EBF and EABF parameters were calculated for such glasses in the gamma photon energy ranging from 0.015 to $15 \mathrm{MeV}$. The variation of BF parameters with different mean free path (up to $40 \mathrm{mfp}$ ) was also evaluated. The current study will be useful for the estimation of the dose deposited in such shielding glasses. The radiation dosimetry property of the synthesized glasses was investigated by irradiating the samples with different gamma doses from ${ }^{60} \mathrm{Co}$ source and then measuring the TL intensity. The TL depth parameters were determined by deconvoluting the TL glow curves with the help of Computerized Glow Curve Deconvolution (CGCD) technique and Chen's peak- shape method and compared with each other. An optimum sample was chosen for studying linearity, sensitivity, fading analysis and reproducibility.

\section{Experimental}

Melt quench technique was employed to prepare zinc bismuth barium borosilicate glasses with a matrix: (60-x) $\mathrm{B}_{2} \mathrm{O}_{3}-20 \mathrm{SiO}_{2}-\mathrm{xBi}_{2} \mathrm{O}_{3}-12 \mathrm{ZnO}-8 \mathrm{BaO}$ in $\mathrm{mol} \%$ (with $\mathrm{x}=0$, 2, 4, 6, 8, 10 and $12 \mathrm{~mol} \%$ ). The chemical powders of high purity $(>99 \%)$ were weighed and crushed together to obtain a homogenous fine powder. Alumina crucible containing that powder was kept inside a muffle furnace with temperature $1300-1320^{\circ} \mathrm{C}$, for two hours until the powder melted to form a highly viscous liquid. By quenching that liquid melt upon a brass slab maintained at $350{ }^{\circ} \mathrm{C}$, bubble- free glass samples were obtained. Later the glasses were subjected to annealing for three hours at $350{ }^{\circ} \mathrm{C}$ (below glass transition temperature $\mathrm{T}_{\mathrm{g}}$ ) for getting rid of any thermal stress developed during melting. The fabricated glasses were cut to a desired shape and polished well to a thickness of $3 \mathrm{~mm}$ on Bainpol- VT polishing machine using silicon carbide abrasive sheets ${ }^{2}$. The densities of the synthesized glasses were determined using Archimedes' principle by taking distilled water as an immersion liquid on a Contech Analytical Weighing balance. The sample codes, $\mathrm{Bi}_{2} \mathrm{O}_{3}$ concentration, molecular weight, density, and molar volume values of the fabricated glasses are listed in Table 1 . The DTA and TGA curves for ZBiB-0, 4, 8 and $\mathrm{ZBiB}-12$ glasses were recorded with a heating rate of $10^{\circ} / \mathrm{min}$ from room temperature to $900^{\circ} \mathrm{C}$ by using Hitachi STA7200 Thermal Analyser. Microhardness (H) measurement was done in three trials with the help of diamond indentations taken in Micro- Vickers Hardness tester (Matsuzawa MMT X 7 A) at a dwell time of 15 seconds. The indentation images were taken on CARL ZEISS FESEM 03-81 instrument.

Table 1. Physical parameters of the synthesized glass samples.

\begin{tabular}{ccccccccc}
\hline Sample code & ZBiB-0 & ZBiB-2 & ZBiB-4 & ZBiB-6 & ZBiB-8 & ZBiB-10 & ZBiB-12 \\
\hline $\mathrm{Bi}_{2} \mathrm{O}_{3}$ concentration $(\mathrm{mol} \%)$ & 0 & 2 & 4 & 6 & 8 & 10 & 12 \\
\hline Average molecular weight, $\mathrm{M}(\mathrm{g} / \mathrm{mol})$ & 75.82 & 85.14 & 94.46 & 103.78 & 113.10 & 122.42 & 131.74 \\
\hline Density, $\rho(\mathrm{g} / \mathrm{cc})( \pm 0.01)$ & 2.65 & 3.07 & 3.12 & 3.32 & 3.63 & 3.83 & 3.85 \\
\hline Molar volume, $\mathrm{V}_{\mathrm{m}}\left(\mathrm{cm}^{3}\right)$ & 27.51 & 26.79 & 28.67 & 29.12 & 30.07 & 29.52 & 31.35 \\
\hline
\end{tabular}


A software known as Photon Shielding and Dosimetry (Phy-X/PSD) was utilised to get the theoretical values of MAC values for the synthesized samples. For experimental validation of the theoretical results, the radiation intensity measurements were carried out using a gamma ray spectrometer (NUCLEONIX, GR611M) consisting of a detector and NUCLEONIX, MC 1000U multi-channel analyser. The experimental set up used for this measurement has been explained along with a diagrammatic representation by D. K Gaikwad et al. ${ }^{16}$. The glass samples polished to the thickness $(\mathrm{t})$ range of $0.2-0.4 \mathrm{~cm}$ were chosen. The radioisotopes ${ }^{133} \mathrm{Ba},{ }^{137} \mathrm{Cs}$ and ${ }^{60} \mathrm{Co}$ emitting gamma radiation of 0.356 , $0.662,1.173$ and $1.33 \mathrm{MeV}$, respectively were procured from Bhabha Atomic Research Centre (BARC), Mumbai, India. The MAC values were determined with the help of Lambert- Beer law ${ }^{16}$, by measuring the initial $\left(\mathrm{I}_{0}\right)$ and final intensity (I) (after passing through the samples) as follows,

$\mu_{m}=\frac{\mu}{\rho}=\ln \left(\frac{I_{0}}{I}\right) \frac{1}{\rho t}$

Here in Equation 1, $\mu$ represents linear attenuation coefficient, while $\rho$ and t represent the density and thickness of the glass samples. The BF parameters for these glasses were also determined theoretically in gamma energy range of 0.015 $15 \mathrm{MeV}$ using PSD/ Phy-X software. The calculation steps followed by the software in calculating $\mathrm{Z}_{\mathrm{eq}}$ and $\mathrm{BF}$ parameters have been explained by Şakar et al. ${ }^{17}$, Harima et al. ${ }^{6}$ and Sayyed et al. ${ }^{5}$. The powdered glass samples were irradiated with gamma radiation inside a Gamma Chamber-5000 maintained at room temperature by using ${ }^{60} \mathrm{Co}$ radioisotope with dose rate of $5 \mathrm{kGy} / \mathrm{h}$. Thermoluminescence measurements were done with Nucleonix $10091 \mathrm{TL}$ reader at the heating rate of $2.85 \mathrm{~K} / \mathrm{s}$.

\section{Results and Discussion}

\subsection{Thermal analysis}

Thermal properties of the ZBiB glass series were studied by means of Differential Thermal Analysis (DTA) and Thermogravimetric Analysis (TGA). DTA measurements were done so as to obtain the characteristic temperatures such as glass transition temperature $\left(\mathrm{T}_{\mathrm{g}}\right)$, onset- crystallization temperature $\left(\mathrm{T}_{\mathrm{x}}\right)$, crystallization temperature $\left(\mathrm{T}_{\mathrm{c}}\right)$ and melting temperature $\left(\mathrm{T}_{\mathrm{m}}\right)$ for $\mathrm{ZBiB}-0,4,8$ and $\mathrm{ZBiB}-12$ glasses. The DTA curves recorded for the chosen glass samples are depicted in Figure 1. $\mathrm{T}_{\mathrm{g}}$ and $\mathrm{T}_{\mathrm{c}}$ values correspond to endothermic peaks and exothermic peaks as shown in Figure 1. Since the $\mathrm{T}_{\mathrm{g}}$ peaks are not much evident for all the samples, the closer view of $\mathrm{T}_{\mathrm{g}}$ peak for $\mathrm{ZBiB}-8$ glass is shown in the inset of Figure 1. The starting point of crystallization peak is taken as $T_{x}$. The melting temperatures were calculated using Kauzmann's two- third rule ${ }^{18,19}$ given by

$$
\frac{\mathrm{T}_{\mathrm{g}}}{\mathrm{T}_{\mathrm{m}}}=0.666
$$

and the values were marked on the DTA curves with arrow marks. Table 2. gives a list of all the characteristic temperatures determined with the help of DTA curves.

DTA curves can also be found useful for finding the thermal stability of the glasses for practical applications. Hruby's criterion given in Equation 3, utilizes the characteristic temperatures marked in DTA curves to determine the thermal stability ${ }^{19}$

$H_{R}=\frac{\left(T_{x}-T_{g}\right)}{\left(T_{m}-T_{x}\right)}$

The calculated $\mathrm{H}_{\mathrm{R}}$ values were high and were noted in Table 2. This suggested higher thermal stability of the synthesized glasses against crystallization process. Some of the other parameters useful for checking thermal stability are

$\mathrm{X}_{1}=\mathrm{T}_{\mathrm{m}}-\mathrm{T}_{\mathrm{g}}$

$\mathrm{X}_{2}=\frac{\mathrm{T}_{\mathrm{x}}}{\mathrm{T}_{\mathrm{m}}}$

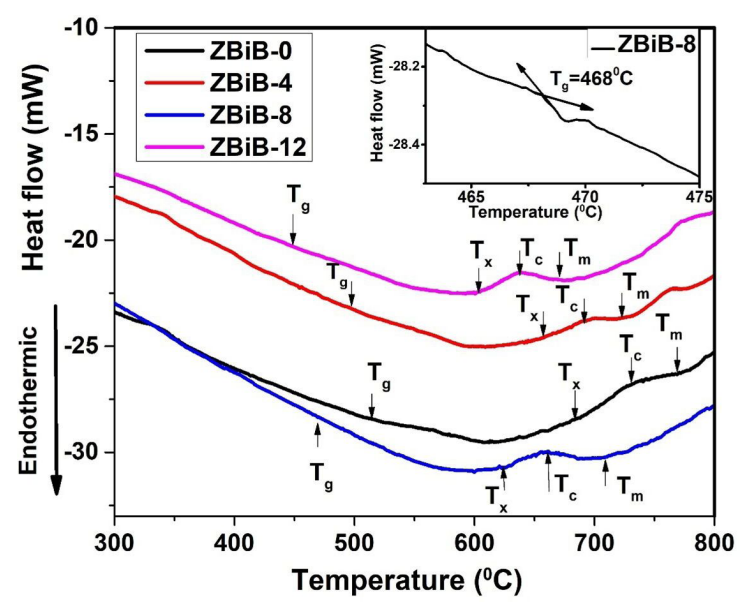

Figure 1. DTA curves of ZBiB-0,4,8,12 glasses in the temperature range of $300-800^{\circ} \mathrm{C}$.

Table 2. Characteristic temperatures and thermal stability parameters of the selected glasses obtained using DTA curves.

\begin{tabular}{cccccccccccc}
\hline Sample & $\mathrm{T}_{\mathrm{g}}\left({ }^{\circ} \mathrm{C}\right)$ & $\mathrm{T}_{\mathrm{x}}\left({ }^{0} \mathrm{C}\right)$ & $\mathrm{T}_{\mathrm{c}}\left({ }^{0} \mathrm{C}\right)$ & $\mathrm{T}_{\mathrm{m}}\left({ }^{0} \mathrm{C}\right)$ & $\mathrm{H}_{\mathrm{R}}$ & $\begin{array}{c}\mathrm{X}_{1}=\mathrm{T}_{\mathrm{m}}-\mathrm{T}_{\mathrm{g}} \\
\left({ }^{0} \mathrm{C}\right)\end{array}$ & $\mathrm{X}_{2}=\mathrm{T}_{\mathrm{x}} / \mathrm{T}_{\mathrm{m}}$ & $\begin{array}{c}\Delta \mathrm{T}_{2} \mathrm{~T}_{\mathrm{x}}-\mathrm{T}_{\mathrm{g}} \\
\left({ }^{0} \mathrm{C}\right)\end{array}$ & $\mathrm{X}_{3}$ & $\mathrm{X}_{4}$ \\
\hline ZBiB-0 & 513 & 684 & 726 & 770 & 1.988 & 257 & 0.888 & 171 & 9.327 & 4.841 \\
\hline ZBiB-4 & 482 & 659 & 698 & 725 & 2.681 & 243 & 0.908 & 177 & 9.521 & 8 \\
\hline ZBiB-8 & 468 & 613 & 661 & 702 & 1.629 & 234 & 0.873 & 145 & 9.914 & 4.707 \\
\hline ZBiB-12 & 448 & 600 & 637 & 672 & 2.111 & 224 & 0.892 & 152 & 8.369 & 5.4 \\
\hline
\end{tabular}


$\Delta \mathrm{T}=\mathrm{T}_{\mathrm{x}}-\mathrm{T}_{\mathrm{g}}$

$\mathrm{X}_{3}=\frac{\left(\mathrm{T}_{\mathrm{x}}-\mathrm{T}_{\mathrm{g}}\right)\left(\mathrm{T}_{\mathrm{c}}-\mathrm{T}_{\mathrm{x}}\right)}{\mathrm{T}_{\mathrm{m}}}$

$X_{4}=\frac{\left(T_{c}-T_{g}\right)}{\left(T_{m}-T_{c}\right)}$

From these calculations, the parameters obtained were listed in Table 2. Here $\Delta \mathrm{T}$ is the term which decides the thermal stability of the glasses and we observed that $\Delta \mathrm{T}$ values in the present case are higher than other bismuth glasses studied by Shaaban et al. ${ }^{20}$, Stehle et al. ${ }^{21}$ and $\mathrm{M}$. Mary et al. ${ }^{22}$. However, decreasing trend of $\Delta \mathrm{T}$ with the increasing $\mathrm{Bi}_{2} \mathrm{O}_{3}$ concentration suggested reduction in glass stability. Similar observation was made by Stehle et al $^{1}$, where $\mathrm{B}_{2} \mathrm{O}_{3}$ was replaced by $\mathrm{Bi}_{2} \mathrm{O}_{3}$. According to Shaaban et al. ${ }^{20}$, the decreasing glass stability with increasing $\mathrm{Bi}_{2} \mathrm{O}_{3}$ may be attributed to increasing number of non- bridging oxygens and replacement of stronger B-O bonds by weaker Bi-O bonds. Studies have also showed the improvement in glass stability of high bismuth glasses by adding $\mathrm{Fe}_{2} \mathrm{O}_{3}$ to the matrix ${ }^{22}$.

The $\mathrm{X}_{4}$ values of $\mathrm{ZBiB}$ glasses calculated from Equation 8 were high and this suggested good glass forming ability in the investigated glass samples. $T_{c}-T_{g}$ values were all greater than $100{ }^{\circ} \mathrm{C}$, which is also a sign of good thermal stability. Small values of $T_{m}-T_{c}$ also signify the hindering of crystallization which means the glasses have good glass forming ability.

TGA measurements done for ZBiB- $0,4,8$ and ZBiB12 samples produce mass loss values while heating the samples in the temperature range of $250-900{ }^{\circ} \mathrm{C}$. TGA curve of ZBiB-8 glass (as an example) is represented in Figure 2. There was no loss of weight below $100{ }^{\circ} \mathrm{C}$ which suggested the absence of water evaporation. The weight loss $\%$ at each step were noted down and the overall weight loss $\%$ in the temperature range of $250-900{ }^{\circ} \mathrm{C}$ for $\mathrm{ZBiB}-0, \mathrm{ZBiB}-4$, $\mathrm{ZBiB}-8$ and $\mathrm{ZBiB}-12$ samples were found to be $2.96 \%$, $2.85 \%, 6.155 \%$ and $3.985 \%$, respectively. It is worth noting that ZBiB-8 glass exhibited significantly higher weight loss \% compared to other three glasses. Similar weight loss of about $6 \%$ was reported by V. Naresh ${ }^{23}$ for bismuth borosilicate glasses in the temperature range of $535-1000{ }^{\circ} \mathrm{C}$, where decomposition of $\mathrm{Bi}_{2} \mathrm{CO}_{3}$ into $\mathrm{Bi}_{2} \mathrm{O}_{3}$ and $\mathrm{CO}_{2}$ as well as phase transformation from $\alpha-\mathrm{Bi}_{2} \mathrm{O}_{3}$ to $\delta-\mathrm{Bi}_{2} \mathrm{O}_{3}$ takes place. Since in $\mathrm{ZBiB}-8$ glasses, $\mathrm{Bi}_{2} \mathrm{O}_{3}$ molecules have replaced $\mathrm{B}_{2} \mathrm{O}_{3}$ molecules remarkably, such phase changes can be expected in this composition leading to higher weight loss. Further addition of $\mathrm{Bi}_{2} \mathrm{O}_{3}$ ( $\mathrm{ZBiB}-12$ glass), has not produced much weight loss while heating which suggested good thermal stabilization in high bismuth glass network.

\subsection{Mechanical studies}

The mechanical properties of ZBiB glasses were explored by calculating Young's modulus (Y) on the basis of Makishima and Mackenzie's theory ${ }^{24}$, according to which

$$
Y=2 G_{t} V_{t}
$$

Here $\mathrm{G}_{\mathrm{t}}$ and $\mathrm{V}_{\mathrm{t}}$ are dissociation energy/volume and packing density of the constituent oxides. The $\mathrm{Y}$ values calculated for ZBiB-0, 4 and 8 glasses are noted in Table 3 along with microhardness $(\mathrm{H})$ values determined using Vickers microhardness tester with $9.8 \mathrm{~N}$ load. It can be noted that $\mathrm{H}$ decrease with increase in bismuth content because of replacing stronger $\mathrm{B}-\mathrm{O}$ bonds by weaker $\mathrm{Bi}-\mathrm{O}$ bonds. This decrease is also in accordance with the decreasing glass transition temperature $\left(\mathrm{T}_{\mathrm{g}}\right)$. The half crack length (L) values for $\mathrm{ZBiB}-0,4$ and 8 glasses around the edges of micro- indentation were measured by recording SEM images and noted down in Table 3. Also, Figure 3 contains SEM image of ZBiB-8 glass surface (as an example). There are many models for calculating fracture toughness $\mathrm{K}_{\mathrm{c}}$ in different materials, but we have chosen a model suggested by Anstis et al. ${ }^{25}$ which says,

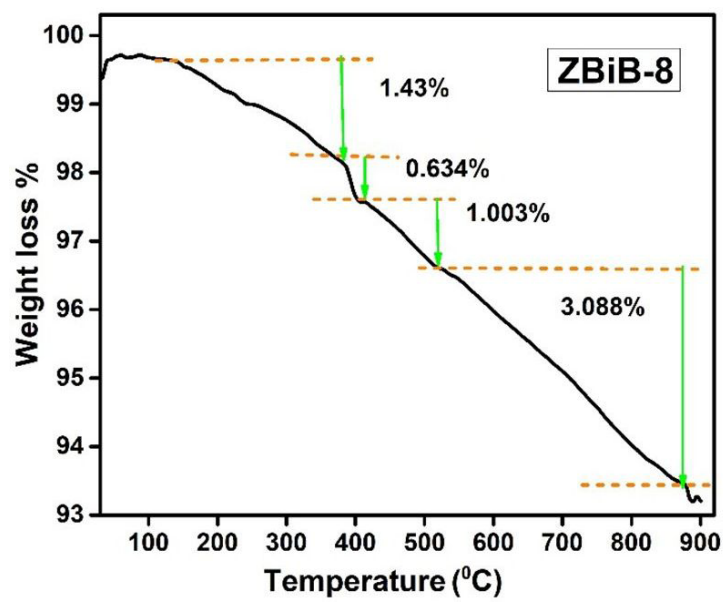

Figure 2. TGA curve for $\mathrm{ZBiB}-8$ glass while heating in the temperature range of $50-900^{\circ} \mathrm{C}$.

Table 3. Young's modulus, Half crack length, Vickers hardness values, fracture toughness and brittleness of selected glass sample at $9.8 \mathrm{~N}$ load.

\begin{tabular}{cccccc}
\hline Sample & $\begin{array}{c}\text { Young's modulus Y } \\
(\mathrm{GPa})\end{array}$ & $\begin{array}{c}\text { Vickers hardness H } \\
(\mathrm{GPa})\end{array}$ & $\begin{array}{c}\text { Half crack length L } \\
(\mu \mathrm{m})\end{array}$ & $\begin{array}{c}\text { Fracture toughness } \\
\mathrm{F}\left(\mathrm{MPa} \mathrm{m}^{1 / 2}\right)\end{array}$ & $\begin{array}{c}\text { Brittleness B } \\
(\mu \mathrm{m})\end{array}$ \\
\hline ZBiB-0 & 57.597 & $4.427 \pm 0.01$ & 46.88 & 0.754 & 5.871 \\
\hline ZBiB-4 & 53.924 & $4.319 \pm 0.011$ & 52.88 & 0.738 & 5.852 \\
\hline ZBiB-8 & 50.102 & $4.194 \pm 0.029$ & 55.96 & 0.676 & 6.203 \\
\hline
\end{tabular}


$\mathrm{K}_{\mathrm{c}}=\left(\frac{\mathrm{Y}}{\mathrm{H}}\right)^{1 / 2} \frac{\mathrm{F}}{\mathrm{L}^{3 / 2}}$

where $\mathrm{F}$ is the load applied. The relation between $\mathrm{F}$ and $\mathrm{L}$ i.e $\mathrm{F}^{\alpha} \mathrm{L}^{3 / 2}$ holds good for many glasses with bismuth borate composition as per the literature. The values of fracture toughness calculated from Equation 10, is found to be in the range of 0.754- 0.676 $\mathrm{MPam}^{1 / 2}$. The increasing half crack length (L) and decreasing fracture toughness $\left(\mathrm{K}_{\mathrm{c}}\right)$ values with $\mathrm{Bi} \mathrm{mol} \%$ (Table 3), indicates easy transmission of cracks through the network and this can be attributed to weak bond strength of Bi-O bonds compared to B-O bonds. Such rapidly decreasing trend of $\mathrm{K}_{\mathrm{c}}$ values on substituting $\mathrm{Bi}_{2} \mathrm{O}_{3}$ with $\mathrm{B}_{2} \mathrm{O}_{3}$ has been reported earlier for lead bismuth borate glasses by $\mathrm{T}$. Watanabe et $\mathrm{al}^{2}{ }^{26}$. Also, it was found that bismuth glasses here exhibited much higher $\mathrm{K}_{\mathrm{c}}\left(\sim 0.23 \mathrm{MPa}^{1 / 2}\right)$ value compared to tellurite glasses found in literature, but the values were matching with those of soda- lime silicate glasses $\left(\sim 0.75 \mathrm{MPa}^{1 / 2}\right)^{26}$.

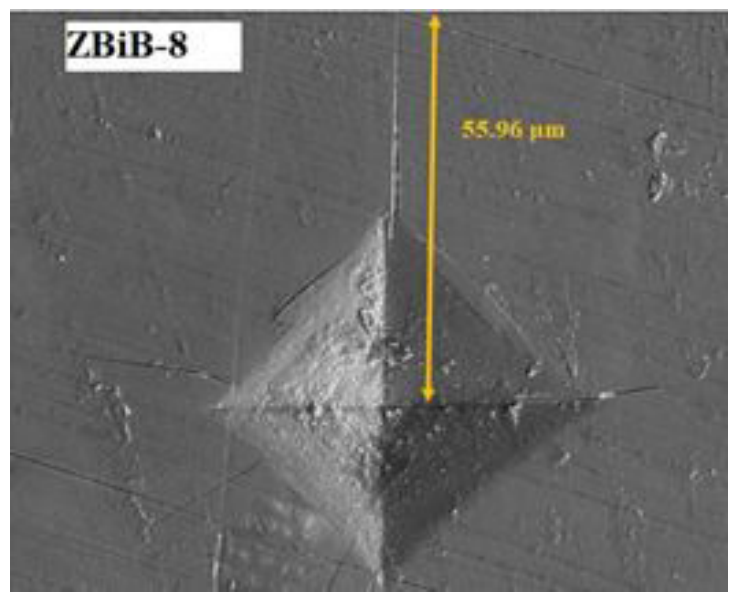

Figure 3. SEM image of micro-indentation for ZBiB- 8 glass at $9.8 \mathrm{~N}$ of load. The yellow line represents the half crack length.

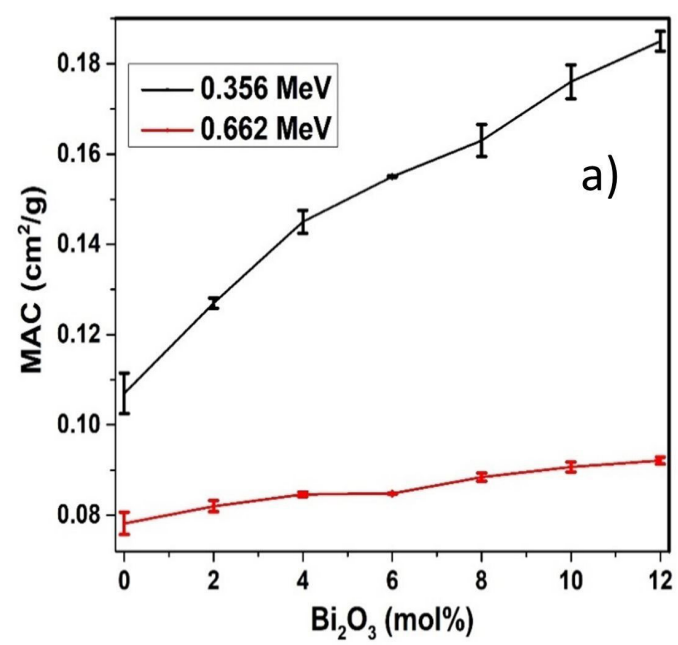

Determining brittleness is a very important aspect of designing glass materials for practical application. Brittleness (B) is defined as ratio of hardness to fracture toughness values as proposed by Lawn and Marshall' ${ }^{27}$,

$\mathrm{B}=\frac{\mathrm{H}}{\mathrm{K}_{\mathrm{c}}}$

The increasing $\mathrm{B}$ values with bismuth addition (Table 3 ) suggested the fragility of these glasses at higher concentration of bismuth mainly because of weaker Bi-O bonds.

\subsection{Gamma radiation shielding}

\subsubsection{Mass attenuation coefficient}

The theoretical MAC values of the chosen glass samples calculated from PSD/Phy-X software at $0.356,0.662$, 1.173 and $1.33 \mathrm{MeV}$ gamma energies are listed in Table 4. The values were comparable with other reported lead, bismuth and concrete shielding materials ${ }^{28}$. The experimentally determined MAC values were calculated using Equation 1 with the help of radiation count results obtained from gamma ray spectrometer. The values are listed in Table 4, which also includes the standard error values for three trial measurements. Very low standard error values as seen in Figure 4 confirmed the accuracy level of the measurements done. The experimental MAC values are in good agreement with the theoretical values with relative difference (RD in \%) between the two values not exceeding 3.5\%. The representation in Figure 4 clearly shows that the MAC values increase with the increase in $\mathrm{Bi}_{2} \mathrm{O}_{3}$ mol\% at each energy, indicating higher radiation attenuation property of $\mathrm{ZBiB}-12$ sample. The increase in MAC values can be attributed to the increasing density values (Table 1) and replacement of lighter ions of boron by heavier ions of bismuth ${ }^{29}$. Also, a decreasing trend followed by MAC values with energy increase gives an implication of photoelectric absorption of the gamma photons at such lower energies.



Figure 4. Graphs showing the dependence of experimental MAC values with $\mathrm{Bi}_{2} \mathrm{O}_{3}$ concentration at $0.356,0.662,1.173$ and $1.33 \mathrm{MeV}$. 


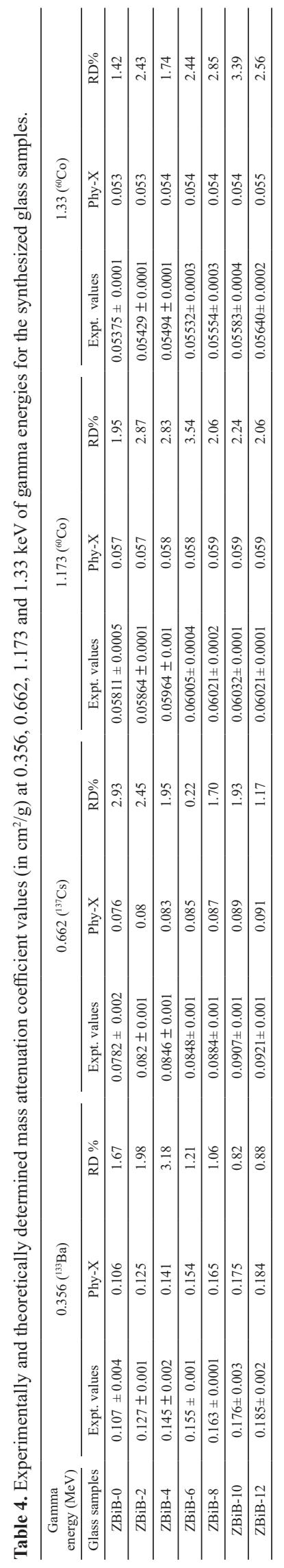




\subsubsection{Equivalent atomic number $\left(Z_{e q}\right)$}

The variation of $Z_{\text {eq }}$ is represented in Figure 5. In this figure, $\mathrm{ZBiB}-12$ sample exhibits maximum $\mathrm{Z}_{\mathrm{eq}}$ values (in the range of 26 to 63 ), while $\mathrm{ZBiB}-0$ exhibits lowest values (in the range of 15 to 32 ). The highest $\mathrm{mol} \%$ and the absence of heavy metal oxide $\left(\mathrm{Bi}_{2} \mathrm{O}_{3}\right)$ in $\mathrm{ZBiB}-12$ and $\mathrm{ZBiB}-0$ samples respectively, are responsible for such kind of behaviour of $\mathrm{Z}_{\mathrm{eq}}$ values. The trend followed by $\mathrm{Z}_{\mathrm{eq}}$ values with the gamma energy is same for all the selected samples as evident in Figure 5. The predominance of photoelectric effect in the low photon energy region is the reason for lower values of $Z_{\text {eq }}$ in that region. The direct proportionality of $Z_{\text {eq }}$ with photon energy in the mid- energy area till $1.02 \mathrm{MeV}$ is due

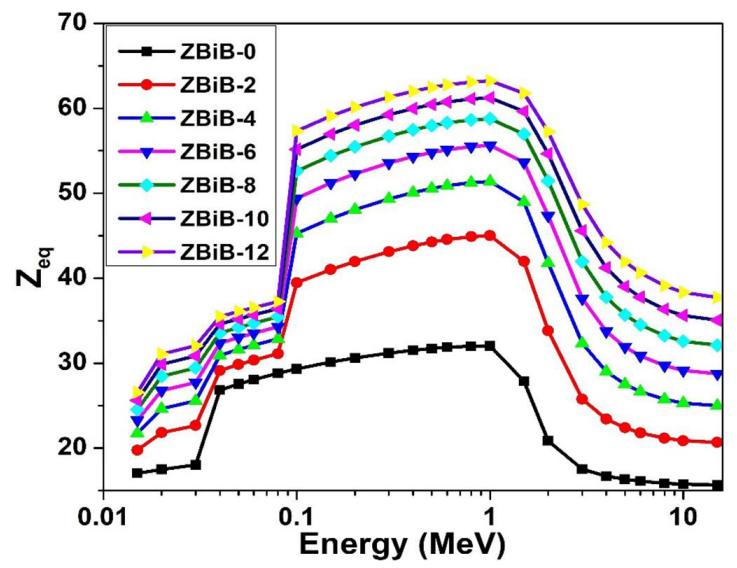

Figure 5. Variation of equivalent atomic number $\left(Z_{\mathrm{eq}}\right)$ values with gamma energy.


to the Compton scattering process ${ }^{30}$, where $Z_{\text {eq }}$ also exhibits maximum values for all the investigated samples. At higher energy (after $1.02 \mathrm{MeV}$ ), the reduction in $\mathrm{Z}_{\mathrm{eq}}$ indicates that the build- up factors depend on chemical composition of the sample due to predominance of pair production process. Therefore, the study in this regard reveals that the highest range of $Z_{\text {eq }}$ exists for $\mathrm{ZBiB}-12$ sample, providing better radiation shielding effect compared to other samples.

\subsection{3. $E B F / E A B F$ variation with photon energy}

Table 5 gives GP fitting parameters for exposure and energy absorbance build-up factors in the case of ZBiB-8 sample (as an example), computed by the PSD software. Using the GP fitting parameters obtained for all the investigated samples, the EBF and EABF values were calculated and their variation with photon energy at different penetration depths $(1,5,10,20,30$ and $40 \mathrm{mfp})$ was represented in Figure 6 and Figure 7 (curves of only selected samples are represented in these figures). Here EBF values increase with increase in penetration depth/thickness of the sample because of the multiple interaction of the gamma photons with the sample particles and photon build-up. The trend followed by EBF is same as that of the concretes and composite materials with high atomic number ${ }^{1,7,8}$. The discontinuities at 0.04 and $0.1 \mathrm{MeV}$ (Figure 6 and Figure 7) correspond to K- absorption edges of $\mathrm{Ba}$ and $\mathrm{Bi}$ respectively ${ }^{2}$. Only in the case of $\mathrm{ZBiB}$ 10 and $\mathrm{ZBiB}-12$ samples, BF curves showed an extra peak at $0.02 \mathrm{MeV}$ which corresponds to $\mathrm{L}_{\mathrm{I}}$ - absorption edge of Bi element ${ }^{31}$. It can also be observed that $\mathrm{L}_{\mathrm{I}}$ - absorption edges in both $\mathrm{ZBiB}-10$ and $\mathrm{ZBiB}-12$ samples are dominant over $\mathrm{K}$ - absorption edge of $\mathrm{Bi}$, which may be due to the

Figure 6. Variation of EBF of the selected glass samples with the gamma energy at different mfps in the range of $0.015-15 \mathrm{MeV}$. 
Table 5. GP fitting parameters for EBF and EABF in the case of ZBiB-8 (as an example) in the energy range of 0.015-15 MeV.

\begin{tabular}{|c|c|c|c|c|c|c|c|c|c|c|}
\hline \multirow{2}{*}{$\frac{\text { Energy }}{\mathrm{MeV}}$} & \multicolumn{5}{|c|}{ G-P Fitting Parameters for EBF } & \multicolumn{5}{|c|}{ G-P Fitting Parameters for EABF } \\
\hline & a & $\mathrm{b}$ & $\mathrm{c}$ & d & $X_{k}$ & a & $\mathrm{b}$ & $\mathrm{c}$ & $\mathrm{d}$ & $\mathrm{X}_{\mathrm{k}}$ \\
\hline $1.50 \mathrm{E}-02$ & -0.428 & 1.005 & 1.349 & 0.303 & 5.913 & -0.425 & 1.005 & 1.347 & 0.300 & 6.503 \\
\hline $2.00 \mathrm{E}-02$ & 0.740 & 1.010 & 0.108 & -0.986 & 10.884 & 0.421 & 1.007 & 0.235 & -0.473 & 13.563 \\
\hline $3.00 \mathrm{E}-02$ & 0.201 & 1.129 & 0.390 & -0.058 & 12.839 & 0.241 & 1.038 & 0.400 & -0.175 & 11.958 \\
\hline 4.00E-02 & 0.180 & 2.184 & 0.327 & -0.071 & 17.964 & 0.162 & 1.216 & 0.364 & -0.193 & 24.572 \\
\hline $5.00 \mathrm{E}-02$ & -0.007 & 1.979 & 0.213 & -0.053 & 12.476 & 0.066 & 1.210 & 0.219 & -0.024 & 10.844 \\
\hline $6.00 \mathrm{E}-02$ & 0.656 & 1.738 & 0.190 & -0.141 & 15.467 & 0.516 & 1.221 & 0.187 & -0.170 & 14.714 \\
\hline $8.00 \mathrm{E}-02$ & 0.503 & 1.445 & 0.222 & -0.189 & 14.203 & 0.410 & 1.275 & 0.225 & -0.180 & 14.200 \\
\hline $1.00 \mathrm{E}-01$ & 0.678 & 1.425 & 0.049 & -0.262 & 14.049 & 0.652 & 1.382 & 0.059 & -0.284 & 13.747 \\
\hline $1.50 \mathrm{E}-01$ & 0.332 & 1.203 & 0.268 & -0.188 & 13.814 & 0.506 & 1.432 & 0.134 & -0.270 & 13.789 \\
\hline $2.00 \mathrm{E}-01$ & 0.190 & 1.208 & 0.460 & -0.102 & 14.287 & 0.380 & 1.540 & 0.227 & -0.219 & 13.857 \\
\hline $3.00 \mathrm{E}-01$ & 0.130 & 1.311 & 0.582 & -0.062 & 13.854 & 0.269 & 1.813 & 0.353 & -0.154 & 13.550 \\
\hline $4.00 \mathrm{E}-01$ & 0.088 & 1.409 & 0.710 & -0.051 & 14.128 & 0.202 & 2.065 & 0.482 & -0.134 & 13.854 \\
\hline $5.00 \mathrm{E}-01$ & 0.062 & 1.474 & 0.794 & -0.041 & 14.107 & 0.146 & 2.090 & 0.602 & -0.103 & 13.876 \\
\hline $6.00 \mathrm{E}-01$ & 0.044 & 1.516 & 0.852 & -0.031 & 13.798 & 0.116 & 2.145 & 0.673 & -0.086 & 13.700 \\
\hline $8.00 \mathrm{E}-01$ & 0.027 & 1.568 & 0.919 & -0.025 & 13.667 & 0.082 & 2.174 & 0.768 & -0.068 & 13.608 \\
\hline $1.00 \mathrm{E}+00$ & 0.016 & 1.582 & 0.962 & -0.022 & 13.314 & 0.065 & 2.145 & 0.823 & -0.060 & 13.525 \\
\hline $1.50 \mathrm{E}+00$ & -0.009 & 1.538 & 1.072 & -0.011 & 13.643 & 0.038 & 2.007 & 0.924 & -0.050 & 13.541 \\
\hline $2.00 \mathrm{E}+00$ & -0.012 & 1.555 & 1.094 & -0.012 & 13.096 & 0.027 & 1.879 & 0.969 & -0.045 & 13.164 \\
\hline $3.00 \mathrm{E}+00$ & 0.000 & 1.557 & 1.065 & -0.028 & 12.838 & 0.034 & 1.720 & 0.956 & -0.057 & 13.208 \\
\hline $4.00 \mathrm{E}+00$ & 0.014 & 1.517 & 1.023 & -0.038 & 13.234 & 0.041 & 1.583 & 0.937 & -0.062 & 13.680 \\
\hline $5.00 \mathrm{E}+00$ & 0.032 & 1.501 & 0.971 & -0.053 & 13.445 & 0.055 & 1.518 & 0.903 & -0.074 & 13.942 \\
\hline $6.00 \mathrm{E}+00$ & 0.038 & 1.461 & 0.960 & -0.057 & 13.508 & 0.057 & 1.444 & 0.902 & -0.074 & 14.159 \\
\hline $8.00 \mathrm{E}+00$ & 0.053 & 1.418 & 0.930 & -0.071 & 13.739 & 0.064 & 1.359 & 0.898 & -0.077 & 14.138 \\
\hline $1.00 \mathrm{E}+01$ & 0.047 & 1.356 & 0.963 & -0.064 & 14.004 & 0.055 & 1.285 & 0.933 & -0.069 & 14.336 \\
\hline $1.50 \mathrm{E}+01$ & 0.047 & 1.296 & 1.010 & -0.063 & 14.392 & 0.059 & 1.215 & 0.964 & -0.069 & 14.664 \\
\hline
\end{tabular}
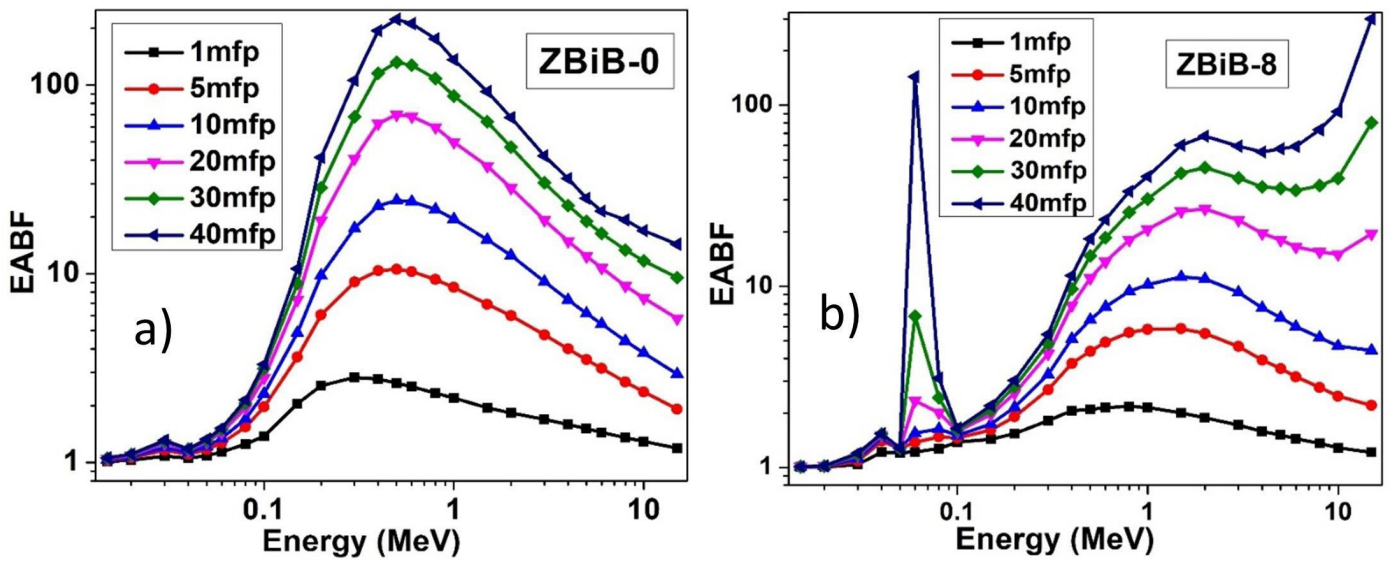

Figure 7. Variation of EABF of ZBiB-0 and ZBiB-8 glass samples with the gamma energy at different mfp in the range of $0.015-15 \mathrm{MeV}$. 
orientational changes arising in the glass structure for higher concentration of bismuth.

From the graphs in Figure 6 and Figure 7, it is clear that in the low energy region, $\mathrm{BF}$ values are small (order of 1) and large in high energy region. The variation of BF values with energy can be explained based on three photon interaction processes. The interaction probabilities mainly depend on the photon energy and the atomic number of the interacting materials. Except ZBiB-12, all the samples produce low and almost same $\mathrm{BF}$ values for initial gamma energy values $(0.015,0.02$ and $0.03 \mathrm{MeV})$ at all penetration depths because of the predominance of photoelectric absorption process. At these gamma energies, maximum gamma photons are absorbed the glass samples leading to minimum build-up factors. Additionally, in the intermediate range of gamma energy, BF values show increasing trend because of multiple scattering events occurring by Compton scattering process. This intermediate energy range varies from one sample to another due to the variation in $\mathrm{Bi}_{2} \mathrm{O}_{3}$ concentration. For bismuth- less glass ( $\left.\mathrm{ZBiB}-0\right)$, the build- up factor increases up to $0.6 \mathrm{MeV}$ due to Compton scattering and then decreases for further increase in energy due to pair production process. Such kind of behaviour is also observed in certain brick materials reported by Singh and Badiger ${ }^{7}$. But bismuth glasses exhibit increasing trend of EBF till $1 \mathrm{MeV}$ and give almost constant values for higher energies. Also, a slight rise in EBF values can be noticed for higher penetration depths (30 and $40 \mathrm{mfp}$ ). This suggests that on adding bismuth to the glass network, the increase in $Z_{\text {eq }}$ causes the gamma photons to behave differently in high energy region. Similar behaviour of bismuth glasses has been reported before by Sayyed et al., where very large EBF values were observed in pair- production region for large penetration depth ${ }^{5}$. As a result, photons may escape from the glass material at low penetration depth and undergo multiple scattering at large penetration depth.

It can be noted from Figures 6 and 7 that both the buildup factors (EBF and EABF) followed the same pattern for all the glasses. However, EBF and EABF values are not same at all energies There is a large difference between EBF and $\mathrm{EABF}$ values in the intermediate energy region due to Compton scattering dominance. At low energy, both have almost same values. Also, there is possibility that EBF is greater than $\mathrm{EABF}$ in some region and lesser in other region. If $\mathrm{EBF}$ is more than $\mathrm{EABF}$, then the absorption of photons in air is same as the materials having low $Z_{\mathrm{eq}}$. The sample with lowest range of $Z_{\text {eq }}$ (15 to 32) is $\mathrm{ZBiB}-0$ and highest $\mathrm{Z}_{\mathrm{eq}}$ range (26 to 63) is $\mathrm{ZBiB}-12$. If for a sample, $\mathrm{EABF}$ is greater than $\mathrm{EBF}$, then there is more photon absorption inside the sample rather than at the surface of the sample EABF. For $0.6 \mathrm{MeV}$ energy photons, it is seen that EABF is higher than $\mathrm{EBF}$ for both $\mathrm{ZBiB}-0$ and $\mathrm{ZBiB}-12$ samples at $40 \mathrm{mfp}$ of penetration depth.

\subsubsection{EBF variation with penetration depth}

In Figure 8, the variation of EBF values with the penetration depths at different gamma energies $(0.015,1.5$, 3 and $15 \mathrm{MeV}$ ) are depicted. Clearly, for different energies, the order of increase in EBF values with $\mathrm{Bi}$ content was different. At lower penetration depths up to around $10 \mathrm{mfp}$,
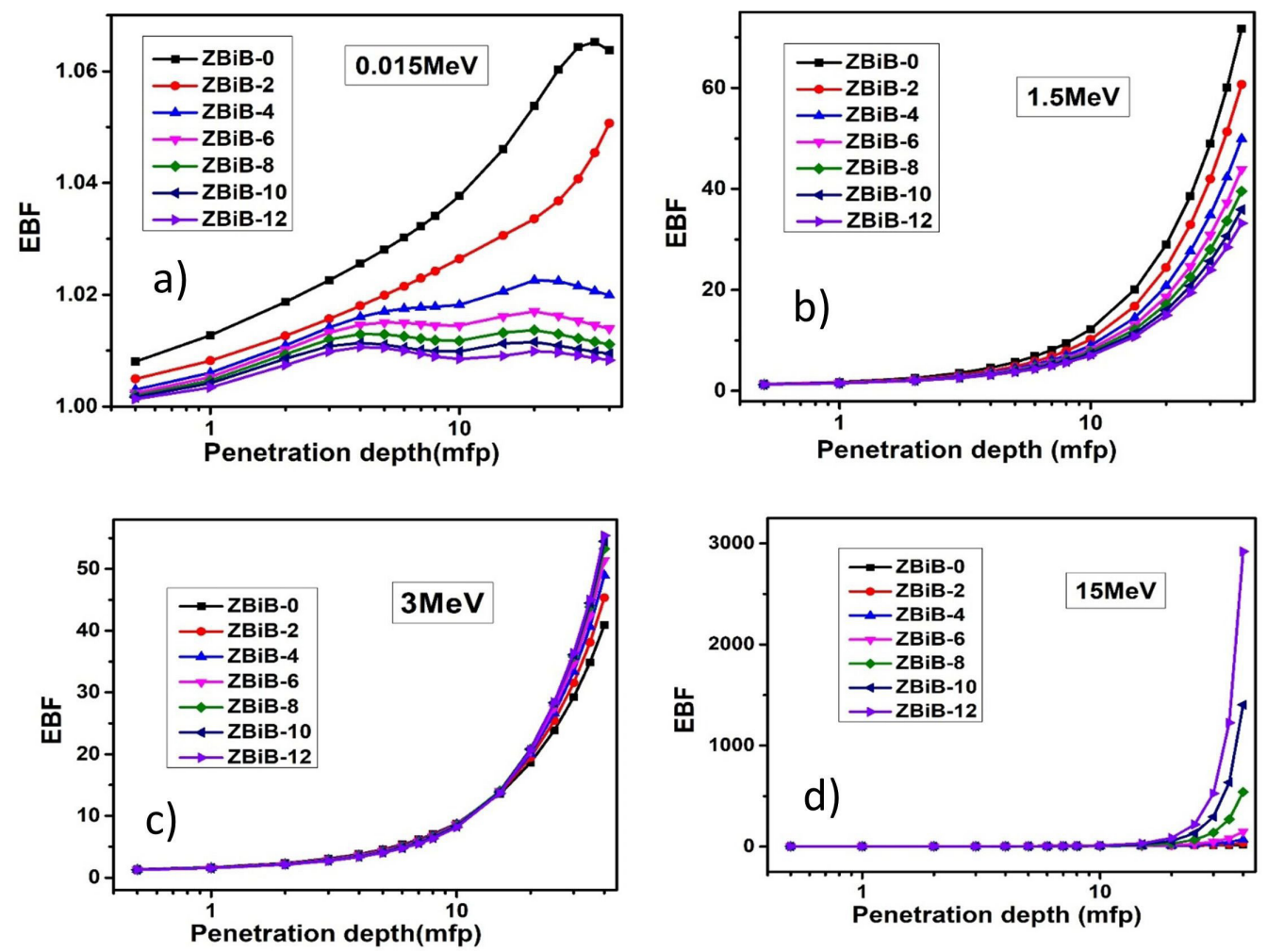

Figure 8. Variation of EBF values of fabricated glass samples with the penetration depth for $0.015,1.5,3$ and $15 \mathrm{MeV}$ energies. 
the EBF values for all the samples are independent of the composition. The dependence of EBF values on the composition arises for higher depths as indicated in Figure 8. When the gamma energy provided is low $(0.015$ and $1.5 \mathrm{MeV})$, the EBF values obtained for less bismuth- containing samples are higher than the samples containing more Bi. Whereas in case of 3 and $15 \mathrm{MeV}$, the $\mathrm{ZBiB}-12$ sample provided highest EBF values.

At photon energy of $15 \mathrm{MeV}$, the EBF values for penetration depth of $40 \mathrm{mfp}$ in case of ZBiB-0, 6 and 12 samples were found to be $17.7,147$ and 2920 respectively. At $0.6 \mathrm{MeV}\left({ }^{137} \mathrm{Cs}\right.$ equivalent), the $\mathrm{EBF}$ values for $\mathrm{ZBiB}-0$, 6 and 12 samples for $40 \mathrm{mfp}$ penetration depth were found to be $113,18.3$ and 10.8 respectively.

\subsection{Thermoluminescence studies}

\subsubsection{TL glow curves}

Figure 9 displays the overlaid TL glow curves measured for powdered $\mathrm{ZBiB}$ glass samples irradiated with gamma dose of $5 \mathrm{kGy}$ of $1.25 \mathrm{MeV}$ energy. ZBiB-0 sample produces highest TL peak intensity. Due to the presence of divalent $\mathrm{Zn}^{2+}$ ions in this glass network, more number of electron and hole trapping centers exist initially ${ }^{14}$. When $\mathrm{Bi}_{2} \mathrm{O}_{3}$ is added to the network, the TL intensity drops down drastically. Further addition of bismuth decreases the TL intensity (Figure 9), because with $\mathrm{Bi}_{2} \mathrm{O}_{3}$ incorporation, the $\mathrm{Zn}^{2+}$ ions reduce to $\mathrm{Zn}^{+}$ions and do not form Si-O-Zn linkages to polymerize the glass network. $\mathrm{BiO}_{6}$ fragments usually create defect centers in the network. But with the increase in $\mathrm{Bi}^{3+}$ ions, the number of $\mathrm{BiO}_{6}$ fragments decrease, which further increases the degree of polymerization of glass network, leading to increasing non- radiative loss ${ }^{15}$. Among the samples containing higher bismuth concentration ( $>6 \mathrm{~mol} \%$ ), the $\mathrm{ZBiB}-8$ glass produced TL glow curve of comparably higher intensity.

It can be observed from Figure 9, that the glow curves are broad enough and may consist of overlapping peaks inside them due to the existence of multiple trapping centres in the glass network. To acquire further information about such trap centres, the TL glow curves of ZBiB-0,2,4,6 and

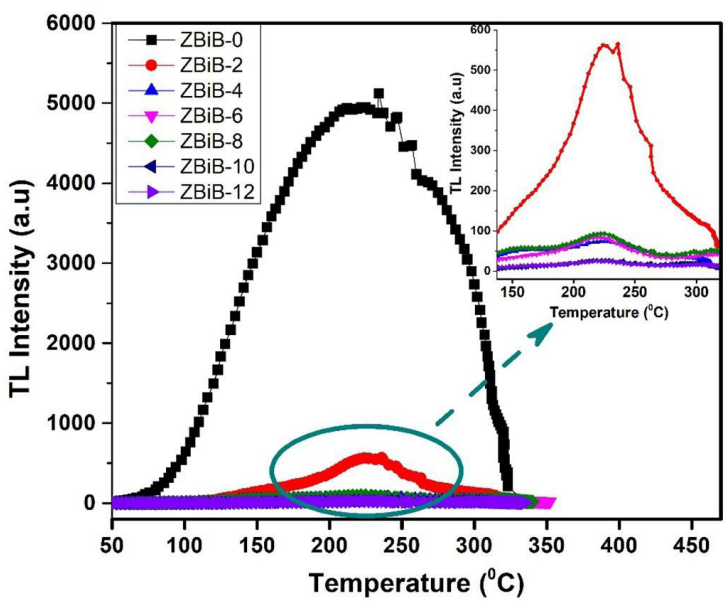

Figure 9. Glow curves of $5 \mathrm{kGy}$ gamma- irradiated glass samples in the temperature range of $250-600 \mathrm{~K}$.
8 samples were deconvoluted using CGCD (Computer Glow Curve Deconvolution) technique with the help of Wolfram Mathematica program. Kitis general order equation was used for least square fitting. The approximated equation for general- order kinetics is given below ${ }^{32,33}$ :

$$
\begin{aligned}
& I(T)=I_{p} b^{\left(\frac{b}{b-1}\right)} \exp \left[\frac{E}{k_{B} T} \frac{T-T_{p}}{T_{p}}\right] \times \\
& {\left[(b-1)\left(1-\frac{2 k_{B} T}{E}\right) \frac{T^{2}}{T_{p}{ }^{2}} \exp \left(\frac{E}{k_{B} T} \frac{T-T_{p}}{T_{p}}\right)+1+(b-1)\left(\frac{2 k_{B} T}{E}\right)\right]^{-\frac{b}{b-1}}}
\end{aligned}
$$

Where $I_{p}$ is the intensity of the peak, $b$ is the order of kinetic, $E$ is the energy of activation, $\mathrm{k}_{\mathrm{B}}$ is Boltzmann- constant and $\mathrm{T}_{\mathrm{p}}$ is the temperature corresponding to the peak. Figure of Merit (FOM) less than 5\% was used to judge the goodness of fit curve. On fitting the curve, the program provides the exact values of order of kinetics (b), trap depth or activation energy $(\mathrm{E}$ in $\mathrm{eV})$ and peak temperature $\left(\mathrm{T}_{\mathrm{p}}\right.$ in $\left.\mathrm{K}\right)$. The escape frequency factor $(\mathrm{S})$ and lifetime $(\mathrm{t})$ of the trapped charges were calculated using the following equations ${ }^{33}$ :

$$
\begin{aligned}
& S=\frac{\beta E}{k_{B} T^{2}\left[1+\frac{(b-1) 2 k_{B} T_{p}}{E}\right]} \exp \left(\frac{E}{k_{B} T_{p}}\right) \\
& \tau=S^{-1} \exp \left(\frac{E}{k_{B} T}\right)
\end{aligned}
$$

where $\beta$ is the heating rate $(2.85 \mathrm{~K} / \mathrm{sec})$ and room temperature T was $300 \mathrm{~K}^{32}$.

The values of $b, T_{p}, E, S$, and $t$ for different peaks in TL glow curves of $\mathrm{ZBiB}-0,2,4,6$ and 8 glasses were tabulated in Table 6. Also, Figure 10 illustrates the deconvoluted glow curves of selected glass samples (ZBiB-0 and ZBiB-8). The charges trapped in the temperature region of $420-430 \mathrm{~K}$ $\left(147-157^{\circ} \mathrm{C}\right)$ had very small activation energy and lifetime (in the order of $10^{-4}$ year) for $0-6 \mathrm{~mol} \%$ of bismuth samples. In the case of $\mathrm{ZBiB}-0$, the charges trapped at $550.75 \mathrm{~K}$ had highest activation energy $(0.956 \mathrm{eV})$ and the corresponding half- life was calculated to be 14.7 years. Whereas in $\mathrm{ZBiB}-8$ sample, the trap center at $577.4 \mathrm{~K}$ provided activation energy and the lifetime of $0.991 \mathrm{eV}$ and 87 years, respectively. This indicates the feasibility of using $\mathrm{ZBiB}-8$ sample for radiation dose measurement and it was taken as optimized sample for further analysis. Although the TL intensity of ZBiB-0 sample is higher than $\mathrm{ZBiB}-8$, the presence of high temperature deeper trap centers in $\mathrm{ZBiB}-8$ and bismuth is an advantage for both shielding and dosimetry application.

Another method known as Chen's peak shape method ${ }^{34}$ is most commonly accepted for analyzing the TL glow curves theoretically. With the help of deconvoluted TL glow curves in Figure 10, the lower and higher temperatures $\left(\mathrm{T}_{1}\right.$ and $\left.\mathrm{T}_{2}\right)$ at half maximum for each TL peak was noted and used for the calculation of following terms: $\omega=\mathrm{T}_{2}-\mathrm{T}_{1}, \tau=\mathrm{T}_{\mathrm{p}}-\mathrm{T}_{1}$ and 
Table 6. TL parameters ( $b, E, T_{p}, S$ and $\tau$ ) corresponding to the three TL peaks in the case of $5 \mathrm{kGy}$ irradiated ZBiB- $0,2,4,6$ and ZBiB- 8 samples.

\begin{tabular}{|c|c|c|c|c|}
\hline Open window (5kGy) & TL parameters & Peak 1 & Peak 2 & Peak 3 \\
\hline ZBiB-0 & $\mathrm{b}$ & 1.13 & 1.02 & 1.08 \\
\hline \multirow[t]{4}{*}{ FOM $(\%)=3.76$} & $\mathrm{E}(\mathrm{eV})$ & 0.528 & 0.558 & 0.956 \\
\hline & $\mathrm{T}_{\mathrm{p}}(\mathrm{K})$ & 428.9 & 485.7 & 550.75 \\
\hline & $\mathrm{S}\left(\mathrm{s}^{-1}\right)$ & $0.305 \times 10^{6}$ & $0.126 \times 10^{6}$ & $248.02 \times 10^{6}$ \\
\hline & $\tau$ (year) & $7.709 \times 10^{-4}$ & $6.098 \times 10^{-3}$ & 14.703 \\
\hline ZBiB-2 & $\mathrm{b}$ & 1.5 & 1.005 & 1.1 \\
\hline \multirow[t]{4}{*}{ FOM $(\%)=4.7638$} & $\mathrm{E}(\mathrm{eV})$ & 0.63 & 0.77 & 0.73 \\
\hline & $\mathrm{T}_{\mathrm{p}}(\mathrm{K})$ & 434 & 500 & 553 \\
\hline & $\mathrm{S}\left(\mathrm{s}^{-1}\right)$ & $4.525 \times 10^{6}$ & $16.34 \times 10^{6}$ & $1.191 \times 10^{6}$ \\
\hline & $\tau$ (year) & $2.688 \times 10^{-3}$ & 0.167 & 0.488 \\
\hline ZBiB-4 & $\mathrm{b}$ & 1.5 & 1.005 & 1.05 \\
\hline \multirow[t]{4}{*}{ FOM $(\%)=4.78$} & $\mathrm{E}(\mathrm{eV})$ & 0.769 & 0.77 & 0.79 \\
\hline & $T_{p}(K)$ & 430.8 & 496.5 & 554 \\
\hline & $\mathrm{S}\left(\mathrm{s}^{-1}\right)$ & $267.49 \times 10^{6}$ & $18.52 \times 10^{6}$ & $4.43 \times 10^{6}$ \\
\hline & $\tau$ (year) & $9.84 \times 10^{-3}$ & 0.147 & 1.336 \\
\hline ZBiB-6 & $\mathrm{b}$ & 1.5 & 1.005 & 1.05 \\
\hline \multirow[t]{4}{*}{ FOM $(\%)=4.78$} & $\mathrm{E}(\mathrm{eV})$ & 0.75 & 0.77 & 0.72 \\
\hline & $\mathrm{T}_{\mathrm{p}}(\mathrm{K})$ & 433 & 481 & 530 \\
\hline & $\mathrm{S}\left(\mathrm{s}^{-1}\right)$ & $34.32 \times 10^{6}$ & $1.543 \times 10^{6}$ & $1.858 \times 10^{6}$ \\
\hline & $\tau$ (year) & $5.315 \times 10^{-3}$ & 0.017 & 0.2128 \\
\hline ZBiB-8 & $\mathrm{b}$ & 1.5 & 1.006 & 1.03 \\
\hline \multirow[t]{4}{*}{$\mathrm{FOM}(\%)=4.483$} & $\mathrm{E}(\mathrm{eV})$ & 0.88 & 0.666 & 0.991 \\
\hline & $T_{p}(K)$ & 423.2 & 492.8 & 577.4 \\
\hline & $\mathrm{S}\left(\mathrm{s}^{-1}\right)$ & $9379.96 \times 10^{6}$ & $1.583 \times 10^{6}$ & $162.241 \times 10^{6}$ \\
\hline & $\tau$ (year) & 0.0205 & 0.0309 & 87.04 \\
\hline
\end{tabular}
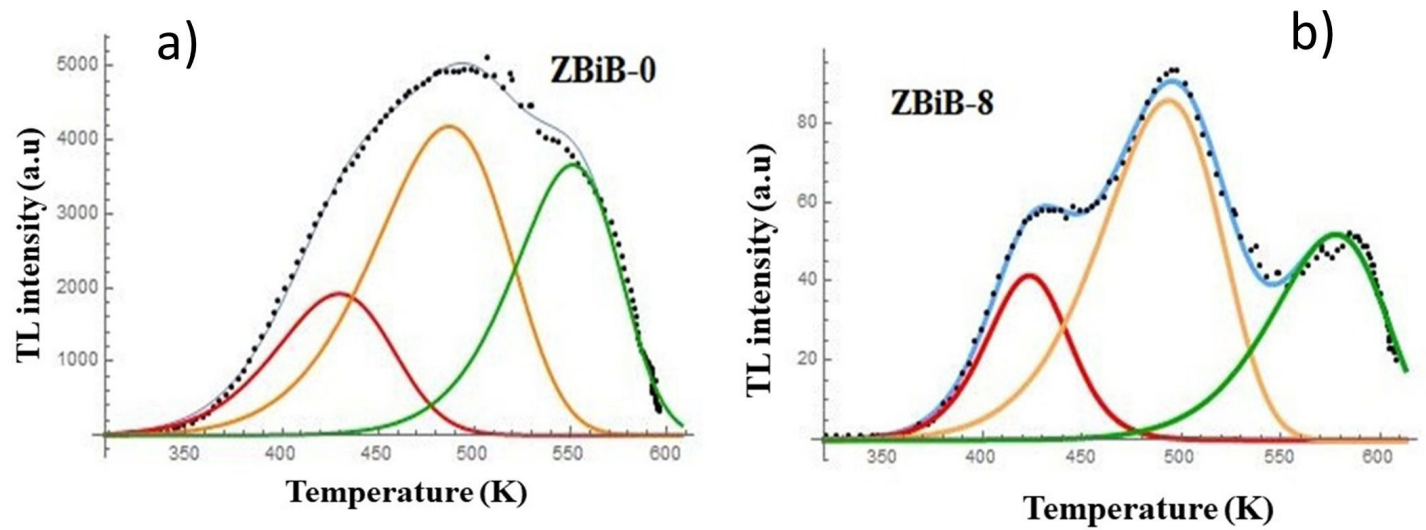

Figure 10. The deconvoluted glow curves of 5 kGy irradiated ZBiB-0 and ZBiB- 8 glasses obtained using CGCD technique.

$\delta=\mathrm{T}_{2}-\mathrm{T}_{\mathrm{p}}$. Order of kinetics was calculated from a geometrical factor, $\mu_{\mathrm{g}=} \delta / \omega$. The calculated $\mu_{\mathrm{g}}$ values suggested that all the peaks in all the samples follow general order kinetics. Finally, the activation energy or trap depth, $\mathrm{E}_{\delta}, \mathrm{E}_{\omega}$ and $\mathrm{E}_{\tau}$ was determined using Chen's equation ${ }^{34}$,

$E_{\alpha}=C_{\alpha}\left(\frac{k T_{p}^{2}}{\alpha}\right)-b_{\alpha}\left(2 k T_{p}\right)$

Where $\mathrm{k}$ is Boltzmann constant, $\mathrm{T}_{\mathrm{m}}$ is peak temperature, $\alpha$ represents $\delta, \omega$ and $\tau$ in different case and $C_{\alpha}$ values are calculated from following equations ${ }^{35}$,

$$
C_{\tau}=1.51+3\left(\mu_{g}-0.42\right) ; b_{\tau}=1.58+4.2\left(\mu_{g}-0.42\right)
$$

$C_{\delta}=0.976+7.3\left(\mu_{g}-0.42\right) ; b_{\tau}=0$

$C_{\tau}=2.52+10.2\left(\mu_{g}-0.42\right) ; b_{\tau}=1$

Activation energy is the average of $\mathrm{E}_{\delta}, \mathrm{E}_{\omega}$ and $\mathrm{E}_{\tau}$. On the other hand, the escape frequency factor and lifetime of 
trapped charges were calculated from Equations 13 \& 14, respectively by substituting these values of activation energies. The trap parameters determined using Chen's peak shape method were listed in Table 7, and it was observed that the values were almost same as those calculated from CGCD method. However, small differences in $\mathrm{E}$ values give rise to difference in values of $\mathrm{S}$ and $\mathrm{t}$ due to the existence of $\mathrm{E}$ term in the exponent of Equations $13 \& 14$.

\subsubsection{Linearity of TL dose response}

Linearity of dose response is an important factor to determine the suitability of a TLD in different radiation application. On this regard, ZBiB-8 glass was irradiated with various gamma doses in the range of $0.25-30 \mathrm{kGy}$ dose and TL measurement was done. The integrated TL intensity values were plotted against the gamma doses and represented in Figure 11. It can be observed that ZBiB- 8 sample showed linear response for the doses till $5 \mathrm{kGy}$. The increase in TL intensity is due to the increase in the number of radiative centers. The TL response up to $5 \mathrm{kGy}$ was taken and linear regression coefficient was found to be 0.989 , which confirms a good linear behavior of ZBiB-8 glass till high dose ( $5 \mathrm{kGy})$. The TL response got saturated for doses higher than $5 \mathrm{kGy}$. The reason behind such TL quenching is "non-monotonic dose-dependence' where the number of non- radiative centers raise beyond the radiative centers at higher doses ${ }^{36}$.

\subsubsection{Sensitivity and minimum detectable dose}

Sensitivity of a TLD is usually determined to characterize its efficiency and it is the TL intensity per unit mass per unit dose, which is equal to the slope of graph of integrated TL intensity per unit mass against gamma dose (Figure 12) ${ }^{10}$. As a result, the sensitivity of $\mathrm{ZBiB}-8$ glass in the dose range of $0.25-5 \mathrm{kGy}$ was 12393 counts $\mathrm{g}^{-1} \mathrm{kGy}^{-1}$, which substantiates the possibility of using $\mathrm{ZBiB}-8$ glass as a dosimeter in this range.

Detecting a TL signal of low intensity is essential when the irradiated material approaches background level ${ }^{10}$. With the knowledge of standard deviation of integrated TL intensity $\sigma_{b}$ of the background TL signal of non- irradiated ZBiB-8 glass, the minimum detectable dose (MDD) for ZBiB-8 can be calculated using the threshold equation ${ }^{37}$,

$$
D_{o}=3 \sigma_{b} F
$$

Here F (calibration factor) is reciprocal of the sensitivity of that sample. Thus, the calculated MDD was $37 \mathrm{~Gy}$, which

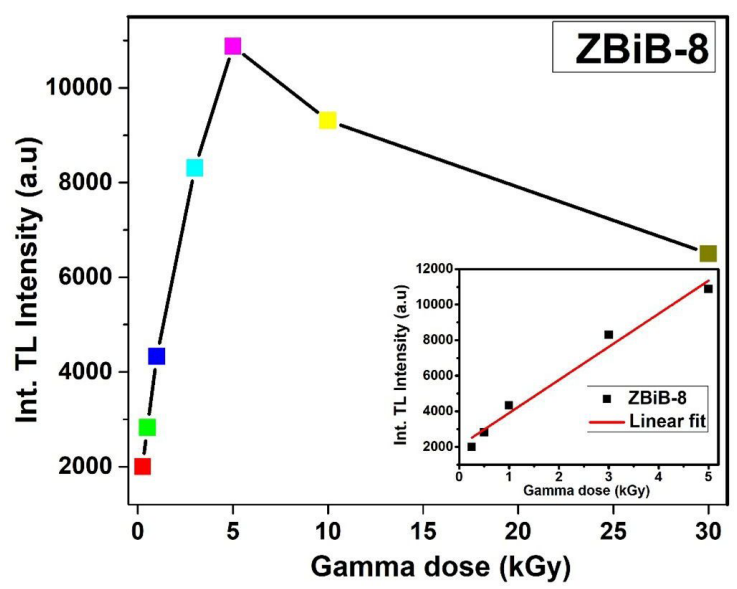

Figure 11. TL dose response curve for $\mathrm{ZBiB}-8$ glass in the dose range of 0.25 to $30 \mathrm{kGy}$.

Table 7. TL trap parameters calculated for 5 kGy irradiated ZBiB-0, 2, 4, 6 and ZBiB-8 samples glasses using Chen's peak shape method.

\begin{tabular}{|c|c|c|c|c|c|c|c|c|}
\hline \multirow{2}{*}{ Sample code } & \multirow{2}{*}{ Peaks } & \multirow{2}{*}{$\begin{array}{c}\text { Peak } \\
\text { temperature } \\
\mathrm{T}_{\mathrm{p}}(\mathrm{K})\end{array}$} & \multicolumn{4}{|c|}{ Activation energy $(\mathrm{eV})$} & \multirow{2}{*}{$\begin{array}{l}\text { Frequency } \\
\text { factor, } \mathrm{s}\left(\mathrm{s}^{-1}\right)\end{array}$} & \multirow{2}{*}{$\begin{array}{c}\text { Half -life } \\
\text { (year) }\end{array}$} \\
\hline & & & $\mathrm{E}_{\tau}$ & $\mathrm{E}_{\delta}$ & $\mathrm{E}_{\omega}$ & $\mathrm{E}$ & & \\
\hline \multirow{3}{*}{ ZBiB-0 } & 1 & 428.9 & 0.553 & 0.624 & 0.589 & 0.589 & $3.05 \times 10^{6}$ & $8.29 \times 10^{-4}$ \\
\hline & 2 & 485.7 & 0.598 & 0.68 & 0.638 & 0.639 & $1.57 \times 10^{6}$ & $1.10 \times 10^{-2}$ \\
\hline & 3 & 550.75 & 0.993 & 0.994 & 0.966 & 0.964 & $2.47 \times 10^{8}$ & 20.88 \\
\hline \multirow{3}{*}{ ZBiB-2 } & 1 & 434 & 0.36 & 0.257 & 0.322 & 0.313 & $1.43 \times 10^{3}$ & $4.07 \times 10^{-5}$ \\
\hline & 2 & 500 & 0.851 & 0.916 & 0.88 & 0.884 & $3.05 \times 10^{8}$ & 0.76 \\
\hline & 3 & 553 & 0.694 & 0.7833 & 0.737 & 0.738 & $1.95 \times 10^{6}$ & 0.41 \\
\hline \multirow{3}{*}{ ZBiB-4 } & 1 & 430.8 & 0.789 & 0.836 & 0.816 & 0.814 & $1.18 \times 10^{9}$ & $1.2 \times 10^{-2}$ \\
\hline & 2 & 496.5 & 0.831 & 0.888 & 0.861 & 0.860 & $1.99 \times 10^{8}$ & 0.45 \\
\hline & 3 & 554 & 0.742 & 0.813 & 0.776 & 0.777 & $4.32 \times 10^{6}$ & 0.84 \\
\hline \multirow{3}{*}{ ZBiB-6 } & 1 & 433 & 0.647 & 0.708 & 0.68 & 0.678 & $2.75 \times 10^{7}$ & $2.8 \times 10^{-3}$ \\
\hline & 2 & 481 & 0.692 & 0.762 & 0.727 & 0.727 & $1.54 \times 10^{7}$ & $3.4 \times 10^{-2}$ \\
\hline & 3 & 530 & 0.712 & 0.776 & 0.743 & 0.743 & $4.31 \times 10^{6}$ & 0.22 \\
\hline \multirow{3}{*}{ ZBiB-8 } & 1 & 423.2 & 1.001 & 1.009 & 1.010 & 1.006 & $3.47 \times 10^{11}$ & $7.5 \times 10^{-2}$ \\
\hline & 2 & 492.8 & 0.679 & 0.751 & 0.714 & 0.714 & $7.52 \times 10^{6}$ & $4.3 \times 10^{-2}$ \\
\hline & 3 & 577.4 & 0.981 & 1.013 & 1.001 & 0.998 & $1.9 \times 10^{8}$ & 99.45 \\
\hline
\end{tabular}


suggests the suitability of dose as low as 30 Gy during high dose measurement.

\subsubsection{Thermal fading}

Loss in TL signal over a period of time is known as fading and this mainly depends on the trap depth and the temperature at which the TLD materials are stored ${ }^{38}$. An ideal TLD must have low fading effect and this is possible when the traps are deep enough to trap the charges for a longer time, so that there is no recombination of charges ${ }^{35}$. The fading behavior of ZBiB-8 glass is studied by irradiating a set of samples with $5 \mathrm{kGy}$ dose and recording the TL glow curve at different interval of days such as 1, 7,15 and 30 days and illustrated in Figure 13. In one day alone, the TL signal faded to $37 \%$. Then the fading on $7^{\text {th }}, 15^{\text {th }}$ and $30^{\text {th }}$ days were $39 \%$, $56 \%$ and $67 \%$ respectively. This indicated the presence of shallow traps in the investigated glass.

\subsubsection{Reproducibility}

Thermal treatment done on the TLD material to counteract its irradiation effects is known as annealing and this is to check the reproducibility or reusability of the TLD, by

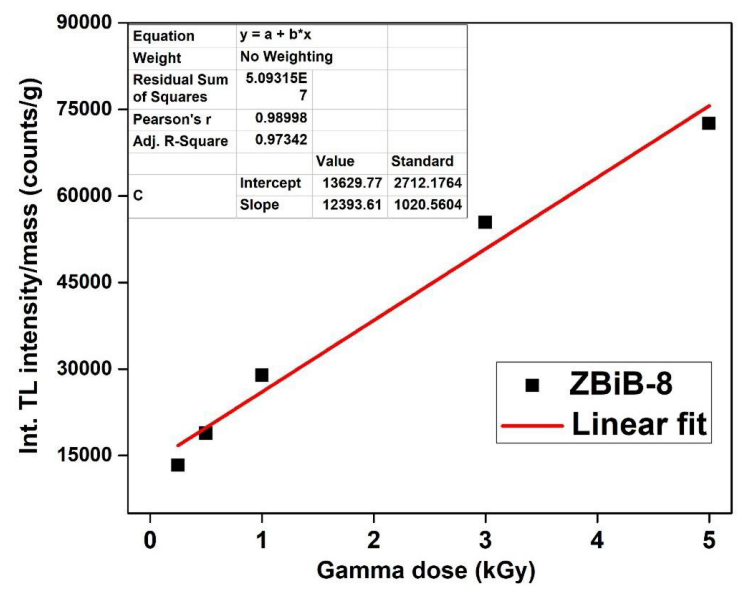

Figure 12. Plot of integrated TL intensity per unit mass for ZBiB-8 glass at gamma doses from $0.25-5 \mathrm{kGy}$.

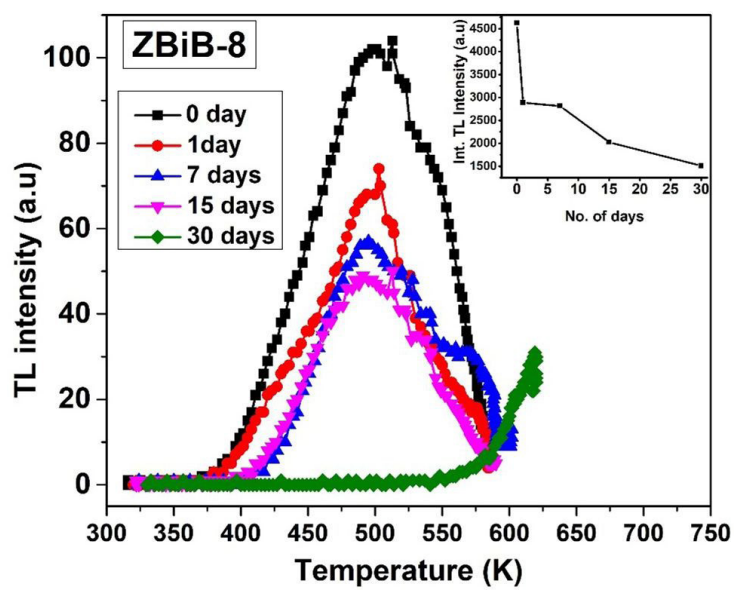

Figure 13. Thermally faded TL intensity curves of ZBiB-8 glass over a period of month. removing the dosimetric traps of residual signal ${ }^{39}$. To find the proper annealing condition (temperature and time) for ZBiB-8 glass, it was subjected to $5 \mathrm{kGy}$ dose of gamma rays initially and TL was measured. Then, a set of three ZBiB-8 glasses were irradiated with $5 \mathrm{kGy}$ and heated inside an oven at three temperatures such as 323,423 and $523 \mathrm{~K}\left(50,150\right.$ and $\left.250{ }^{\circ} \mathrm{C}\right)$ for a fixed duration of $15 \mathrm{~min}$. TL glow curves were recorded for these three samples (Figure 14) and compared with the non- annealed glow curve. The curve corresponding $323 \mathrm{~K}\left(50^{\circ} \mathrm{C}\right)$ showed lowest standard deviation. With $323 \mathrm{~K}$ as an annealing temperature, another set of three $5 \mathrm{kGy}$ irradiated $\mathrm{ZBiB}-8$ was annealed at different time 15, 30 and 45 minutes. The TL was measured and plotted in Figure 15, in which 15 min curve showed more similarity with the original curve. Therefore, the best annealing condition for reusing the $\mathrm{ZBiB}-8$ glass was heating at $323 \mathrm{~K}$ for 15 minutes.

\subsubsection{Effective atomic number $\left(Z_{\text {eff }}\right)$}

The knowledge of effective atomic number of a dosimeter is essential for its application in radiotherapy mainly because $\mathrm{Z}_{\text {eff }}$ of the TLD material should match with that of human

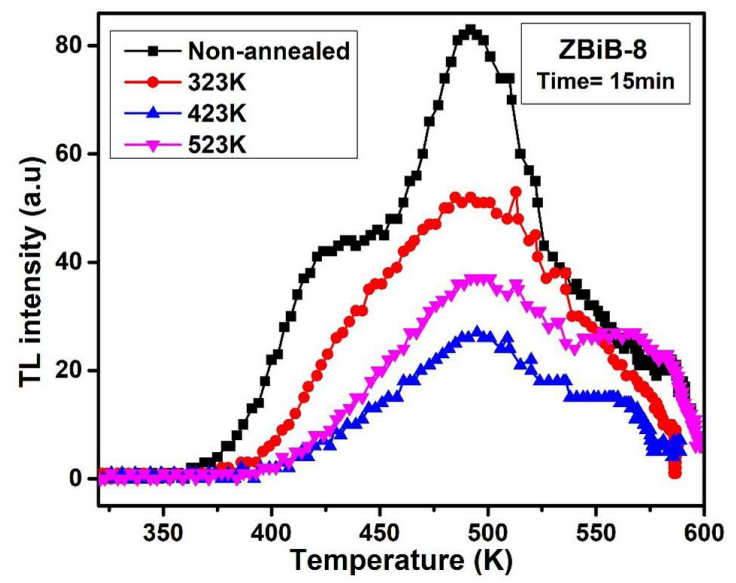

Figure 14. TL glow curve of thermally annealed ZBiB-8 glass at different temperatures for $15 \mathrm{~min}$.

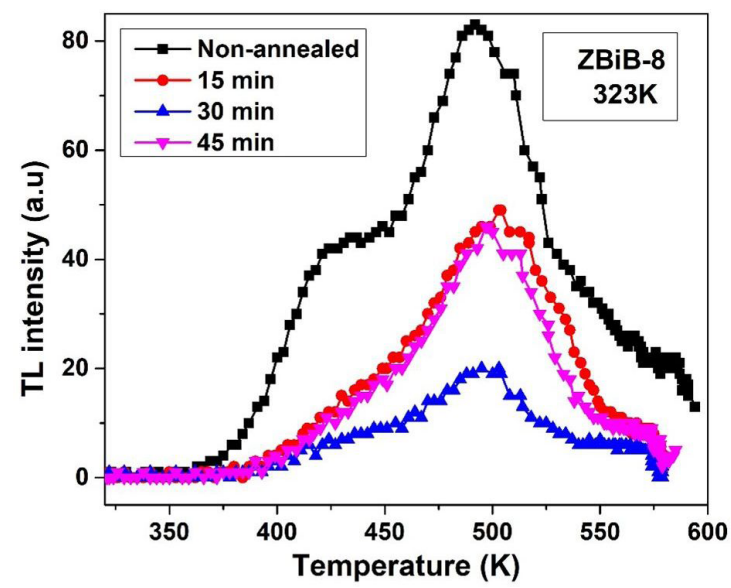

Figure 15. TL glow curve of thermally annealed ZBiB-8 glass at $323 \mathrm{~K}$ for different duration of time. 


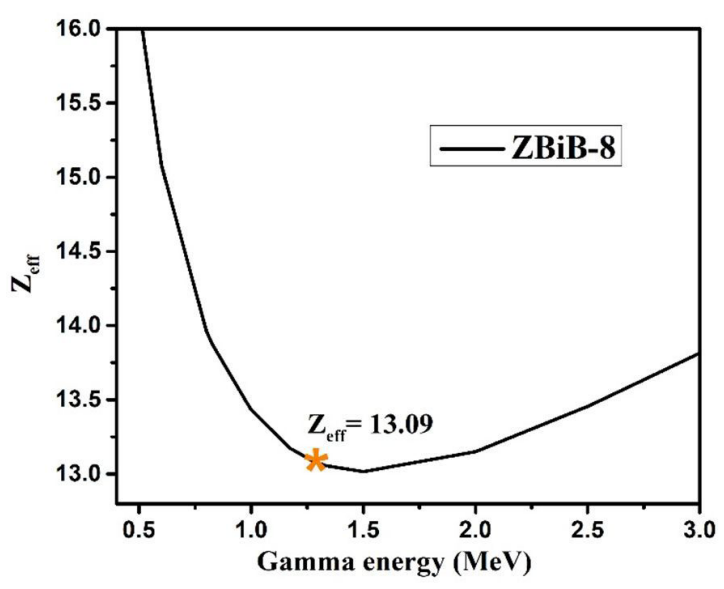

Figure 16. Effective atomic number of $\mathrm{ZBiB}-8$ glass in the gamma energy range of $0.5-3 \mathrm{MeV}$.

tissue $\left(Z_{\text {eff }}=7.5\right)^{35,38}$ while treating cancer or other diseases. For this purpose, the $Z_{\text {eff }}$ values of $\mathrm{ZBiB}-8$ glass, calculated previously using Phy-X/PSD software were plotted with gamma energy in the range of $0.5-3 \mathrm{MeV}$ in Figure 16. Since the TL measurement was done for gamma radiation from ${ }^{60} \mathrm{Co}$ source whose energy is 1.173 and $1.332 \mathrm{MeV}$, the average energy $1.25 \mathrm{MeV}$ was selected for noting down the $\mathrm{Z}_{\text {eff }}$ value. At $1.25 \mathrm{MeV}$, the $\mathrm{Z}_{\text {eff }}$ of $\mathrm{ZBiB}-8$ was observed to be 13.09. This result indicated that this sample was not tissue equivalent and therefore, the deposition of gamma dose in human tissue must be corrected and calibrated. Meanwhile, it can also be noted that $Z_{\text {eff }}$ is not much far from that of human bone $\left(Z_{\text {eff }}=13.8\right)^{38}$ and therefore, can be used in the treatment of bone cancer.

\section{Conclusion}

Overall, the glass samples prepared were found to be thermally and mechanically stable. A detailed investigation on gamma ray shielding parameters has been carried out. The MAC values increased with the bismuth concentration, confirming the superior shielding ability of ZBiB-12 glass. The experimental values of MAC matched with theoretical values with relative difference less than $3.5 \%$. The BF values increased with the increase in penetration depths for all the selected samples. However, the higher EABF value compared to $\mathrm{EBF}$ at $0.6 \mathrm{MeV}$ for $40 \mathrm{mfp}$ penetration depth inside $\mathrm{ZBiB}-12$ indicated that there is higher photon absorption inside ZBiB-12 sample than in air. The dependence of build- up factors on the chemical composition was analysed at different energy regions for maximum penetration depth (40 mfp) and it was found that EBF is increasing with Bi for higher energy (above $3 \mathrm{MeV}$ ) and decreasing for lower energy region (below $3 \mathrm{MeV}$ ). It can be concluded that $\mathrm{ZBiB}-$ 12 sample with its higher value of equivalent atomic number and build up factors is proved to be a better shielding agent compared to other selected samples. But when transparent shielding material is required $\mathrm{ZBiB}-8$ sample would be of more convenience rather than $\mathrm{ZBiB}-12$. The TL quenching role of bismuth has been identified in the present work. However, ZBiB-8 glasses showed comparably higher intensity and half- life for charges trapped at $577.4 \mathrm{~K}\left(304.4{ }^{\circ} \mathrm{C}\right)$ at $5 \mathrm{kGy}$ gamma dose. The calculated TL trap parameters from Chen's peak and CGCD method agreed well with each other. The fading of TL glow curve is significant in $\mathrm{ZBiB}-8$ sample due to the presence of shallow traps. ZBiB-8 exhibited good linearity and sensitivity for TLD application. The TL glow curves of $5 \mathrm{kGy}$ irradiated $\mathrm{ZBiB}-8$ sample can be reproduced by following annealing procedure at $323 \mathrm{~K}$ for 15 minutes. The effective atomic number of $\mathrm{ZBiB}-8$ at $1.25 \mathrm{MeV}$ was found to be 13.08 which is closer to that of bone and therefore found suitable during radio-treatment of bone cancer. In future, it is aimed to improve the TL properties of such glasses by adding rare earth oxides to the network which may also contribute to the enhancement of radiation blocking application.

\section{References}

1. Kavaz E, Nergiz Y. Gamma ray buildup factors of lithium borate glasses doped with minerals Gamma ray buildup factors of lithium borate glasses doped with minerals. J Alloys Compd. 2019;752:61-7.

2. Mariyappan M, Marimuthu K, Sayyed MI, Dong MG, Kara U. Effect $\mathrm{Bi}_{2} \mathrm{O}_{3}$ on the physical, structural and radiation shielding properties of $\mathrm{Er}^{3+}$ ions doped bismuth sodium fluoroborate glasses. J Non-Cryst Solids. 2018;499:75-85.

3. Kaur K, Singh KJ, Anand V. Structural properties of $\mathrm{Bi}_{2} \mathrm{O}_{3}$ $\mathrm{B}_{2} \mathrm{O}_{3}-\mathrm{SiO}_{2}-\mathrm{Na}_{2} \mathrm{O}$ glasses for gamma ray shielding applications. Radiat Phys Chem. 2016;120:63-72.

4. Kaur P, Singh D, Singh T. Heavy metal oxide glasses as gamma rays shielding material. Nucl Eng Des. 2016;307:364-76.

5. Sayyed MI, Lakshminarayana G, Kityk IV, Mahdi MA. Evaluation of shielding parameters for heavy metal fluoride based tellurite-rich glasses for gamma ray shielding applications. Radiat Phys Chem. 2017;139:33-9.

6. Harima Y, Sakamoto Y, Tanaka S, Kawai M. Validity of the geometric-progression formula in approximating Gamma-Ray buildup factors validity of the geometric-progression formula in approximating Gamma-Ray Buildup factors. Nucl Sci Eng. 1986;94:24-35.

7. Singh VP, Badiger NM. Gamma-ray exposure build-up factors of some brick materials. Radioprotection. 2013;48:511-26.

8. Al B, Erdem Ş, Han İ, Sayyed MI. Evaluation the gamma, charged particle and fast neutron shielding performances of some important AISI-coded stainless steels : part II. Radiat Phys Chem. 2020;166:108454.

9. Harima Y. An historical review and current status of buildup factor calculations and applications. Radiat Phys Chem. 1993;41(45):631-72. http://dx.doi.org/10.1016/0969-806X(93)90317-N.

10. Hashim S, Omar RS, Ghoshal SK. Realization of dysprosium doped lithium magnesium borate glass based TLD subjected to 1-100 Gy photon beam irradiations. Radiat Phys Chem. 2019;163:1-10.

11. Giansante L, Martins JC, Nersissian DY, Kiers KC, Kay FU, Sawamura MVY, et al. Organ doses evaluation for chest computed tomography procedures with TL dosimeters: comparison with Monte Carlo simulations. Med Imaging. 2018;20(1):308-20.

12. Ozdemir A, Yegingil Z, Nur N, Kurt K, Tuken T. Thermoluminescence study of Mn doped lithium tetraborate powder and pellet samples synthesized by Solution Combustion Synthesis. J Lumin. 2016;2313(15):30576-7.

13. Omar RS, Wagiran H, Saeed MA. Dosimetric properties of dysprosium doped calcium magnesium borate glass subjected to Co-60 gamma ray. AIP Conf Proc. 1704;2016:040004. 
14. Salama E, Soliman HA, Youssef GM, Hamad S. Thermoluminescence properties of borosilicate glass doped with $\mathrm{ZnO}$. J Lumin. 2017;186:164-9.

15. Ashok J, Kumar JS, Graça MPF, Soares MJ, Reddy MS, Sanyal B, et al. Structural influence of Bi3+ ions on physical properties of $\mathrm{Na} 2 \mathrm{CuSiO} 4$ glasses photoluminescence and thermoluminescence studies. J Non Cryst Solids. 2016;449:50-4.

16. Gaikwad DK, Sayyed MI, Botewad SN, Obaid SS, Khattari ZY, Gawai UP, et al. Physical, structural, optical investigation and shielding featuresof tungsten bismuth tellurite based glasses. J Non Cryst Solids. 2019;503-504:158-68.

17. Şakar E, Özpolat ÖF, Alım B, Sayyed MI, Kurudirek M. Phy-X / PSD: development of a user friendly online software for calculation of parameters relevant to radiation shielding and dosimetry. Radiat Phys Chem. 2019;166:108496.

18. Wagh A, Raviprakash Y, Ajithkumar MP, Upadhyaya V, Kamath SD. Effect of $\mathrm{Sm}_{2} \mathrm{O}_{3}$ on structural and thermal properties of zinc fluoroborate glasses. Trans Nonferrous Met Soc China. 2015;25(4):1185-93.

19. Lakshminarayana G, Kaky KM, Baki SO, et al. Physical, structural, thermal, and optical spectroscopy studies of $\mathrm{TeO}_{2}$ $\mathrm{B}_{2} \mathrm{O}_{3}-\mathrm{MoO}_{3}-\mathrm{ZnO}-\mathrm{R}_{2} \mathrm{O}(\mathrm{R}=\mathrm{Li}, \mathrm{Na}$, and $\mathrm{K}) / \mathrm{MO}(\mathrm{M}=\mathrm{Mg}$, $\mathrm{Ca}$, and $\mathrm{Pb}$ ) glasses. J Alloys Compd. 2017;690:799-816.

20. Shaaban ER, Shapaan M, Saddeek YB. Structural and thermal stability criteria of $\mathrm{Bi}_{2} \mathrm{O}_{3}-\mathrm{B}_{2} \mathrm{O}_{3}$ glasses. J Phys Condens Matter. 2008;20(15):155108.

21. Stehle C, Vira C, Hogan D, Feller S, Affatigato M. Optical and physical properties of bismuth borate glasses related to structure. Phys Chem Glasses. 1998;39(2):83-6.

22. Mary N, Rebours M, Castel E, Vaishnav S, Deng W, Bell AMT, et al. Enhanced thermal stability of high-bismuth borate glasses by addition of iron. J Non-Cryst Solids. 2018;500:14957.

23. Naresh V, Lee N. NIR luminescence and energy transfer kinetics in $\mathrm{Nd}^{3+} / \mathrm{Yb}^{3+}$ co-doped sodium aluminium bismuth fluoro-borosilicate glasses. Ceram Int. 2019;45(17):22649-59.

24. Prabhu NS, Hegde V, Wagh A, Sayyed MI, Agar O, Kamath SD. Physical, structural and optical properties of $\mathrm{Sm}^{3+}$ doped lithium zinc alumino borate glasses. J Non-Cryst Solids. 2019;515:116-24.

25. Anstis GR. Indentation and fracture toughness I. Transformation (Durb). 1981;46:533-8.
26. Watanabe T, Muratsubaki K, Benino Y, Saitoh H, Komatsu T. Hardness and elastic properties of $\mathrm{Bi} 2 \mathrm{O} 3$-based glasses. J. Mater. Sci. 2001;6:2427-33.

27. Lawn BR, Marshall DB. Hardness, toughness, and brittleness: an indentation analysis. J Am Ceram Soc. 1979;62:1-4.

28. Kurudirek M. Heavy metal borate glasses: potential use for radiation shielding. J Alloys Compd. 2017;727:1227-36.

29. Kaur P, Singh D, Singh T. Gamma rays shielding and sensing application of some rare earth doped lead-alumino-phosphate glasses. Radiat Phys Chem. 2018;144:336-43.

30. El-Mallawany R, Sayyed MI, Dong MG, Rammah YS. Simulation of radiation shielding properties of glasses contain $\mathrm{PbO}$. Radiat Phys Chem. 2018;151:239-52.

31. X-ray Anomalous Scattering [homepage on the Internet]. X-ray absorption edges. 1996 [cited 2021, August 11]. Available from: http://skuld.bmsc.washington.edu/scatter/AS periodic.html.

32. Hegde V, Prabhu N, Wagh A, Sayyed MI, Agar O, Kamath SD Influence of $1.25 \mathrm{MeV}$ gamma rays on optical and luminescent features of $\mathrm{Er}^{3+}$ doped zinc bismuth borate glasses. Results Phys. 2019;12:1762-9.

33. Hegde V, Chauhan N, Kumar V, Viswanath CSD, Mahato KK, Kamath SD. Effects of high dose gamma irradiation on the optical properties of $\mathrm{Eu}^{3+}$ doped zinc sodium bismuth borate glasses for red LEDs. J Lumin. 2019;207:288-300.

34. Chen R. On the calculation of activation energies and frequency factors from glow curves. J Appl Phys. 1969;570(40)

35. Prabhu NS, Sharmila K, Somashekarappa HM, Lakshiminarayana G, Mandal S, Sayyed MI, Kamath SD. Thermoluminescence features of $\mathrm{Er}^{3+}$ doped $\mathrm{BaO}-\mathrm{ZnO}-\mathrm{LiF}-\mathrm{B}_{2} \mathrm{O}_{3}$ glass system for high-dose gamma dosimetry. Ceram Int. 2020;46(11):19343-53.

36. Chen R, Lo D, Lawless JL. Non-monotonic dose dependence of thermoluminescence. Radiat Prot Dosimetry. 2006;119:33-6.

37. Paluch-Ferszt M, Kozlowska B, De Souza SO, De Souza LF, Souza DN. Analysis of dosimetric peaks of $\mathrm{MgB}_{4} \mathrm{O}_{7}$ : Dy (40\% Teflon) versus LiF:Mg,Ti TL detectors. Nukleonika. 2016;61(1):49-52.

38. Tajuddin HA, Wanhassan WMS, Abdul Sani SF, Shaharin NS. Thermoluminescent properties of dy doped calcium borate based glass for dose measurement subjected to photon irradiation. EPJ Web Conf. 2017;156:00002.

39. Soliman HA, Salama E. Thermoluminscence characteristics and dosimetric parameters of $\mathrm{Nd}^{+3}$ doped alkali borosilicate glass. Int J Appl Glass Sci. 2018;9(3):435-43. 